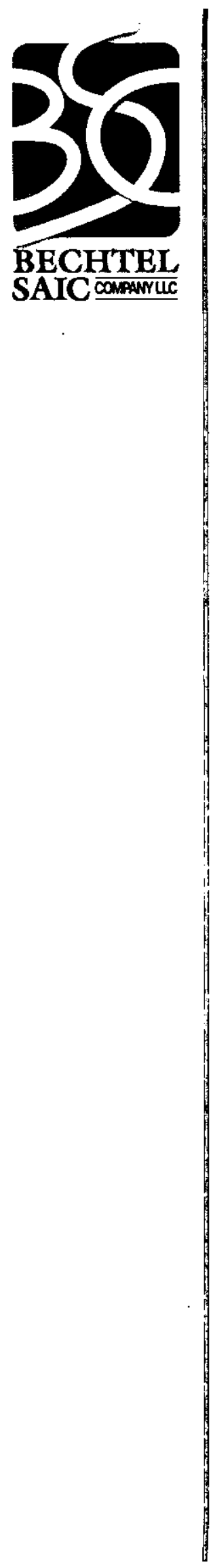

\title{
Preclosure Criticality Analysis Process Report
}

Prepared for:

U.S. Department of Energy

Office of Civilian Radioactive Waste Management

Office of Repository Development

1551 Hillshire Drive

Las Vegas, Nevada 89134-6321

Prepared by:

Bechtel SAIC Company, LLC

1180 Town Center Drive

Las Vegas, Nevada 89144

Under Contract Number

DE-AC28-01RW12101 


\section{DISCLAIMER}

This report was prepared as an account of work sponsored by an agency of the United States Government. Neither the United States Government nor any agency thereof, nor any of their employees, nor any of their contractors, subcontractors or their employees, makes any warranty, express or implied, or assumes any legal liability or responsibility for the accuracy, completeness, or any third party's use or the results of such use of any information, apparatus, product, or process disclosed, or represents that its use would not infringe privately owned rights. Reference herein to any specific commercial product, process, or service by trade name, trademark, manufacturer, or otherwise, does not necessarily constitute or imply its endorsement, recommendation, or favoring by the United States Government or any agency thereof or its contractors or subcontractors. The views and opinions of authors expressed herein do not necessarily state or reflect those of the United States Government or any agency thereof. 
Originator:

\section{Adan 6 Dain}

A. E. Danise

Criticality Department

Originator:

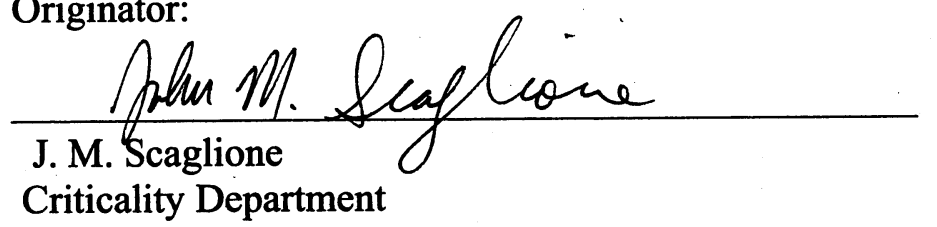

Checker:

Qivillam E. Atutsos in D.L. Newell

D. L. Newell

Criticality Department

Quality Engineering Representative:

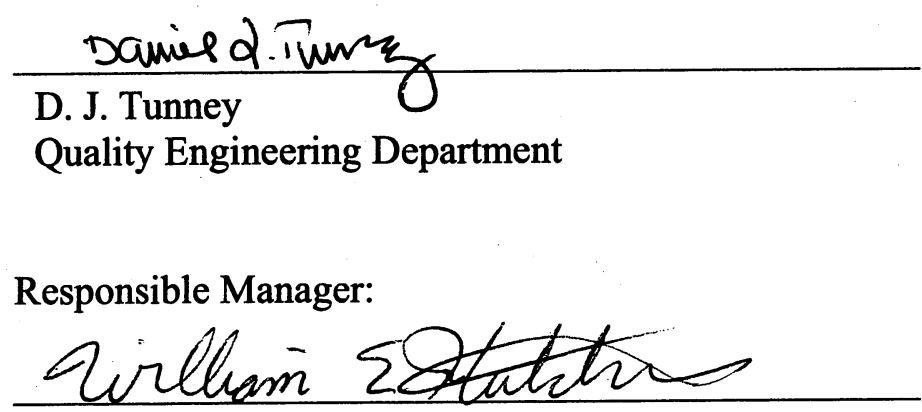

W. E. Hutchins

Manager, Criticality Department

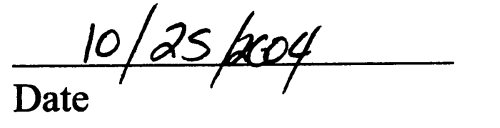

$10 / 25 / 2004$

Date

$10 / 25 / 2004$

Date

$10 / 25 / 2004$

Date

$\frac{10 / 25 / 2004}{\text { Date }}$ 


\section{INTENTIONALLY LEFT BLANK}




\section{CHANGE HISTORY}

\section{Revision Interim}

Number Change N

00

01

02

0

03

04

\section{Description of Change}

09/29/1999 Initial issue.

06/30/2003 This document replaces an earlier version of this document of the same title issued under document identifier B00000000-01717-5705-00132 REV 00. It has also been revised to provide additional information and update to current versions of regulatory guidance documents.

04/15/2004 Document modified to incorporate comments from DOE AP-6.28Q review. It supersedes TDR-EBSNU-000004 REV 01. A black vertical line in the margin indicates changed lines. Modifications were made in the following areas: executive summary, all numbered sections, and Appendix A.

05/21/2004 Document modified to incorporate editorial comments from a licensing management review. It supersedes TDR-EBS-NU-000004 REV 02. A black vertical line in the margin indicates changed lines. Modifications were made in the following areas: Sections 1.1, 1.3, 1.4, 2.2.2, 2.2.8, 3.1, 3.2.2, 3.4.1, 3.5, 3.6.2, and 4.0.

10/19/2004 Document modified to list exceptions to requirements and standards (Section 2.2.3) and to clarify the use of loading curves (Section 3.6.1), as well as update references to current versions. Black vertical lines in the margin indicate changed text. 


\section{INTENTIONALLY LEFT BLANK}




\section{EXECUTIVE SUMMARY}

This report describes a process for performing preclosure criticality analyses for a repository at Yucca Mountain, Nevada. These analyses will be performed from the time of receipt of fissile material until permanent closure of the repository (preclosure period). The process describes how criticality safety analyses will be performed for various configurations of waste in or out of waste packages that could occur during preclosure as a result of normal operations or event sequences. The criticality safety analysis considers those event sequences resulting in unanticipated moderation, loss of neutron absorber, geometric changes, or administrative errors in waste form placement (loading) of the waste package. The report proposes a criticality analyses process for preclosure to allow a consistent transition from preclosure to postclosure, thereby possibly reducing potential cost increases and delays in licensing of Yucca Mountain. The proposed approach provides the advantage of using a parallel regulatory framework for evaluation of preclosure and postclosure performance and is consistent with the U.S. Nuclear Regulatory Commission's approach of supporting risk-informed, performance-based regulation for fuel cycle facilities, Yucca Mountain Review Plan, Final Report ${ }^{\mathrm{a}}$, and 10 CFR Part $63^{\mathrm{b}}$. The criticality-related criteria for ensuring subcriticality are also described as well as which guidance documents will be utilized. Preclosure operations and facilities have significant similarities to existing facilities and operations currently regulated by the U.S. Nuclear Regulatory Commission; therefore, the design approach for preclosure criticality safety will be dictated by existing regulatory requirements while using a risk-informed approach with burnup credit for inpackage operations.

\footnotetext{
${ }^{a}$ NRC (U.S. Nuclear Regulatory Commission) 2003. Yucca Mountain Review Plan, Final Report. NUREG-1804, Rev. 2. Washington, D.C.: U.S. Nuclear Regulatory Commission, Office of Nuclear Material Safety and Safeguards. TIC: 254568.

${ }^{\mathrm{b}} 10$ CFR Part 63. Energy: Disposal of High-Level Radioactive Wastes in a Geologic Repository at Yucca Mountain, Nevada. Readily available.
} 


\section{INTENTIONALLY LEFT BLANK}




\section{CONTENTS}

Page

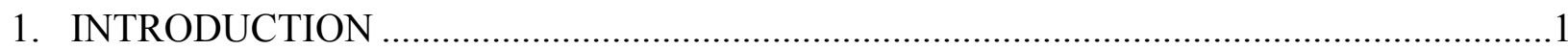

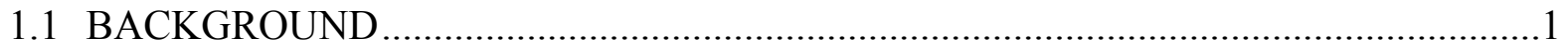

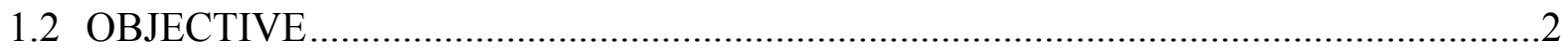

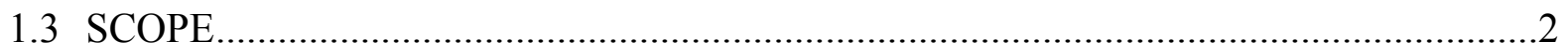

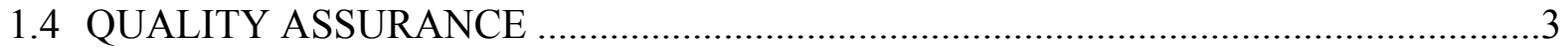

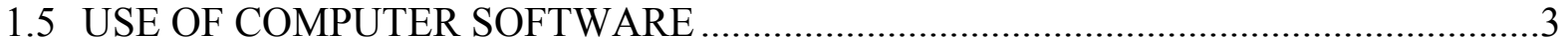

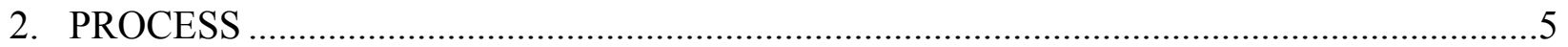

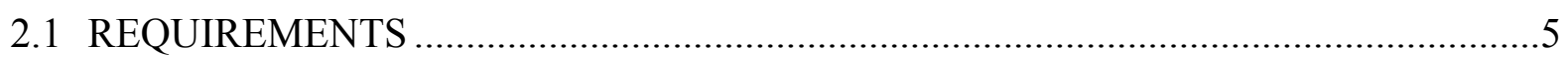

2.2 CRITICALITY CONTROL CRITERIA AND GUIDANCE …................................5

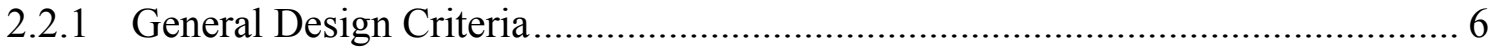

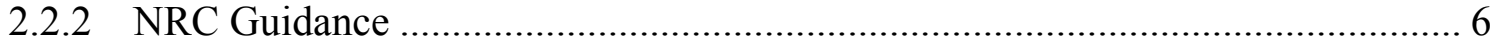

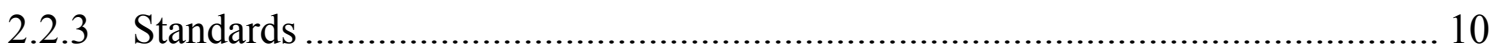

2.2.4 Criticality Analysis Methods and Computer Codes ......................................... 12

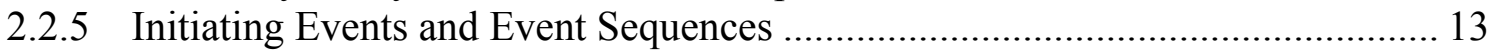

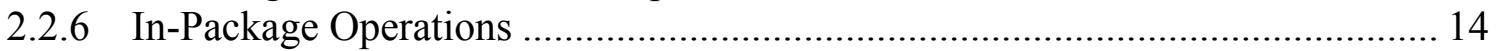

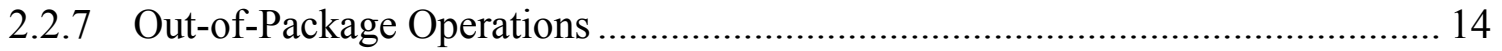

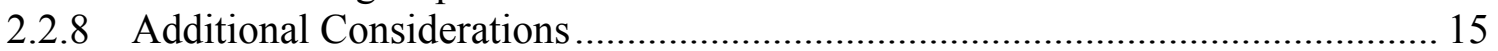

3. CRITICALITY ANALYSIS ................................................................................... 17

3.1 IDENTIFICATION OF CRITICALITY EVENT SEQUENCES AND DESIGN

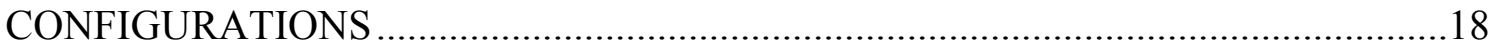

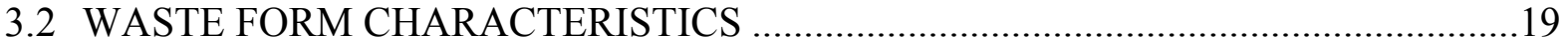

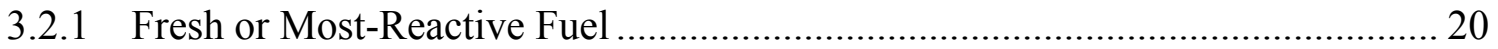

3.2.2 Isotopic Model for CSNF Burnup Credit ........................................................ 20

3.2.3 Requirements for Confirmation of Conservatism ......................................... 22

3.3 EFFECTIVE NEUTRON MULTIPLICATION FACTOR ( $\left.\mathrm{k}_{\mathrm{eff}}\right)$ CALCULATION .......23

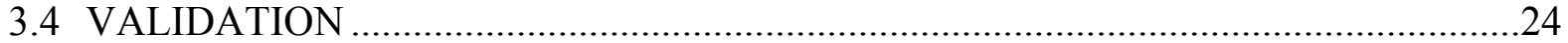

3.4.1 Upper Subcritical Limit Determination........................................................ 24

3.4.2 Upper Subcritical Limit Application ..................................................... 31

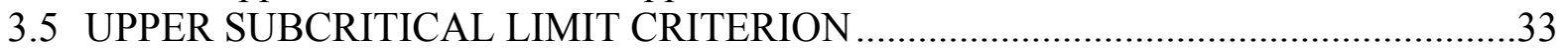

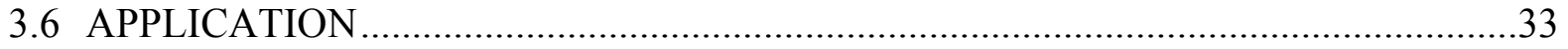

3.6.1 Loading Restrictions for Commercial Spent Nuclear Fuel ............................... 34

3.6.2 Out-of-Package Criticality Safety ............................................................. 35

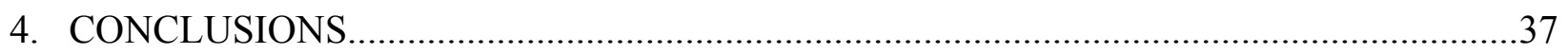

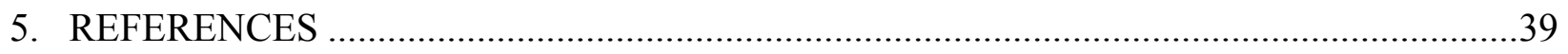

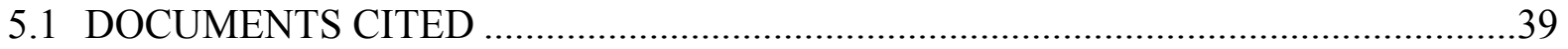

5.2 CODES, STANDARDS, REGULATIONS, AND PROCEDURES ...........................41

APPENDIX A - LOADING OF A WASTE PACKAGE.................................................... A-1 


\section{INTENTIONALLY LEFT BLANK}




\section{FIGURES}

Page

Figure 1. Preclosure Criticality Analysis Process Overview .................................................... 18

Figure 2. Process for Calculating Lower-Bound Tolerance Limits ......................................... 28

Figure A-1. Required Minimum Burnup for 4.0 wt\% Enriched PWR SNF ........................... A-2

Figure A-2. Loading Restrictions for Waste Package ........................................................... A-2

\section{TABLES}

Page

Table 1. NRC Guidance Document Applicability ................................................................. 7

Table 2. Principal Isotopes for CSNF Burnup Credit ........................................................ 22 


\section{INTENTIONALLY LEFT BLANK}




\section{ACRONYMS AND ABBREVIATIONS}

\begin{tabular}{|c|c|}
\hline $\begin{array}{l}\text { ANSI } \\
\text { ANS }\end{array}$ & $\begin{array}{l}\text { American National Standards Institute } \\
\text { American Nuclear Society }\end{array}$ \\
\hline BWR & boiling water reactor \\
\hline $\begin{array}{l}\mathrm{CL} \\
\mathrm{CRC} \\
\mathrm{CSNF}\end{array}$ & $\begin{array}{l}\text { critical limit } \\
\text { commercial reactor critical } \\
\text { commercial spent nuclear fuel }\end{array}$ \\
\hline DOE & U.S. Department of Energy \\
\hline LCE & laboratory critical experiments \\
\hline NRC & U.S. Nuclear Regulatory Commission \\
\hline PWR & pressurized water reactor \\
\hline ROA & range of applicability \\
\hline ROP & range of parameters \\
\hline $\begin{array}{l}\text { SSCs } \\
\text { SNF }\end{array}$ & $\begin{array}{l}\text { structures, systems, and components } \\
\text { spent nuclear fuel }\end{array}$ \\
\hline JSL & upper subcritical limit \\
\hline
\end{tabular}




\section{INTENTIONALLY LEFT BLANK}




\section{INTRODUCTION}

\subsection{BACKGROUND}

This report presents a process for analyzing the potential for criticality during the Yucca Mountain repository preclosure period. This approach can be used to demonstrate compliance with U.S. Nuclear Regulatory Commission (NRC) criticality requirements for handling, storage, and disposal of fissionable material and to support the resolution of Key Technical Issue agreement PRE 7.01 (Reamer 2001, Attachment 1, p. 2). Application of the approach will address applicable NRC design criteria and will also provide input to the preclosure safety analysis that will determine if the repository will meet its overall performance objectives for the repository operations relative to criticality through permanent closure.

This report is written consistent with Yucca Mountain Review Plan, Final Report (NRC 2003), Standard Review Plan for the Review of a License Application for a Fuel Cycle Facility (NRC 2002a, Section 5) issued by the NRC's Office of Nuclear Material Safety and Safeguards, and 10 CFR Part 63, Disposal of High-Level Radioactive Wastes in a Geologic Repository at Yucca Mountain, Nevada. Each of these documents provides a basis for risk-informed compliance demonstrations. While NUREG-1520 (NRC 2002a, Section 5) is not directly applicable to a facility for handling spent nuclear fuel (SNF), the risk-informed approach to criticality analysis in NUREG-1520 (NRC 2002a, Section 5) provides insight into the NRC's approach to risk-informed criticality analysis.

This report provides a single analysis process for determining the criticality potential or effective neutron multiplication factor $\left(\mathrm{k}_{\mathrm{eff}}\right)$ of a configuration during preclosure operations. The process can be applied to design calculations and preclosure safety analyses. The difference between the two types of evaluations is the source of the configurations to be evaluated. Specific deterministically selected design configurations (e.g., fully moderated, most reactive fuel state) are used for design calculations. For the preclosure safety analysis, the probabilities of event sequences are estimated (e.g., Categorization of Event Sequences for License Application [BSC 2004e, Section 7]). For those event sequences that could lead to potentially critical configurations, the probability of reaching such a configuration will be evaluated. If the overall probability of reaching a potentially critical configuration is above the probability threshold, a criticality evaluation of that configuration will be performed.

The proposed approach for out-of-package operations will use the most reactive fuel state (i.e., a fresh fuel assumption with no burnup credit for nonbreeder reactor fuel, or the calculated most reactive state for breeder reactor fuel). The in-package operations will include credit for burnup similar to the postclosure methodology in Disposal Criticality Analysis Methodology Topical Report (YMP 2003). This approach is consistent with 10 CFR Part 63, NRC 2003, and NRC 2002a, Section 5.

Further, this methodology will provide a consistent transition from preclosure to postclosure analyses by using the same general approach, for in-package operations, submitted to the NRC in Disposal Criticality Analysis Methodology Topical Report (YMP 2003), which is intended for postclosure, and uses a risk-informed approach. The proposed approach will provide margin-to- 
criticality for the preclosure time period. Margin-to-criticality is the sum of biases and uncertainties, administrative margins, and reactivity due to use of bounding models and parameters. For the cases described in this report, bounding models and parameters are those that describe a more reactive state than the actual state.

For commercial SNF (CSNF), the primary difference between traditional licensing of fuel cycle facilities away from a reactor and the approach proposed here is the absence of burnup credit in the traditional approach. However, burnup credit is allowed for commercial spent nuclear fuel pools at commercial reactor sites (NRC 1998), storage, and transportation systems (NRC 2002b), which sets a precedent for obtaining burnup credit. Section 3.2.2 shows the similarities and differences between the proposed approach for obtaining burnup credit for preclosure and the approach used for spent nuclear fuel pools at reactor sites.

\subsection{OBJECTIVE}

The objective of this report is to present the approach for performing preclosure criticality analyses for waste packages and repository facilities for the time period beginning with waste form receipt at the surface facility until permanent closure of the subsurface facility. This report may be referenced for work supporting the license application. In addition, it is to provide a single reference for the proposed preclosure criticality analysis methodology and to present that methodology for review. The information presented in this report is not design information that can be used to support procurement, fabrication, or construction.

\subsection{SCOPE}

The scope of this report is to document the approach for performing preclosure criticality safety analyses. The approach will be used to perform criticality safety analyses for various configurations of waste forms, including but not limited to CSNF, defense high-level radioactive waste (e.g., Savannah River Site glass), and U.S. Department of Energy (DOE) SNF that could occur during preclosure as a result of normal operations and event sequences. Because of the characteristics of naval SNF, the Naval Nuclear Propulsion Program will apply a separate methodology to the preclosure analysis for naval fuel. The focus is on safety requirements and the methodology applied to all processes starting with the receipt of transportation casks in the Transportation Cask Receipt/Return Facility and includes everything through the final loading of waste packages for closure and emplacement in the subsurface, and their residence in the subsurface up to the time of permanent closure of the repository.

The preclosure criticality analysis process is a derivative of the criticality analysis methodology presented in Disposal Criticality Analysis Methodology Topical Report (YMP 2003) and its supporting documents, especially Criticality Model (BSC 2004c) and Isotopic Model Report for Commercial SNF Burnup Credit (BSC 2004d). This ensures commonality in the calculational approaches. The essential differences in the methodology from the topical report and the process presented in this report are 1) the source of the configurations to be analyzed, 2) the time period over which events and processes are considered, and 3) the application (i.e., safety analysis versus waste isolation analysis). 
The proposed preclosure criticality analysis process is also applicable to scenarios involving the surface facility and fuel handling operations. It is used to evaluate an eigenvalue (i.e., the effective neutron multiplication factor, $\mathrm{k}_{\mathrm{eff}}$ ). The process describes only how the criticality calculations are performed for a given scenario. Construction of the scenarios to be evaluated is outside the scope of the process. This report has been written to consider many possible features of the process in order to provide flexibility to the user. Note that the user will apply the methodology appropriate to the process under analysis.

The means to prevent and control criticality must be addressed as part of the preclosure safety analysis (10 CFR 63.112[e][6]). The purpose of the preclosure safety analysis is to identify initiating events, their potential event sequences, and their consequences, as well as structures, systems, and components (SSCs); and personnel activities that are important to safety. The identification of preclosure event sequences relating to criticality and the description of the process for the necessary criticality analyses are discussed in more detail in Section 3.1.

The methods and guidance for developing and documenting the preclosure safety analysis are presented by Preclosure Safety Analysis Guide (BSC 2003b) in which Section 11 specifically discusses criticality and refers to this report for the process description. Section 11.1 (BSC 2003b) notes three criticality safety analysis components. First, hazards analyses identify potential failures of SSCs designed to prevent or control the occurrence of a criticality. Next, an event sequence frequency analysis provides the means to evaluate the likelihood of such occurrences and to demonstrate whether or not they are credible. Last, if applicable, neutronics analyses provide design bases to prevent or control criticality, and to verify sub-criticality is maintained during the occurrence of Category 1 or 2 event sequences (10 CFR 63.2).

\subsection{QUALITY ASSURANCE}

The development of this report has been subject to DOE Office of Civilian Radioactive Waste Management Quality Assurance Requirements and Description (DOE 2004) controls, as specified in Technical Work Plan for: Criticality Department Work Packages ACRM01 and NSN002 (BSC 2004a, Section 8). Electronic management of data was accomplished in accordance with the controls specified in the Technical Work Plan for: Risk and Criticality Department Work Packages ACRM01 and NSN002 (BSC 2004a, Section 8).

The work that is to be performed to support the license application using this information will be performed in accordance with the then current versions of NRC regulations and Quality Assurance Requirements and Description (DOE 2004).

\subsection{USE OF COMPUTER SOFTWARE}

No computer software subject to Quality Assurance Requirements and Description (DOE 2004) was used in the development of this report. Graphical figures are presented for illustrative purposes only, and no computations were performed for this report. 
INTENTIONALLY LEFT BLANK 


\section{PROCESS}

Operation of a repository involves a number of distinct but interrelated waste form activities and functions; the major ones include receiving, handling, and packaging.

There are five basic waste form handling operations that may affect preclosure criticality safety:

1. Operations in the carrier/cask handling system

2. Operations in the assembly transfer system

3. Operations in the canister transfer system

4. Operations in the waste package handling system

5. Emplacement of waste packages

It should be noted that the surface facilities are not finalized, but the major functions for criticality analyses are expected to remain the same. Therefore, any reference to a particular building designation or system is only conceptual.

\subsection{REQUIREMENTS}

The regulatory requirements for criticality safety for the Yucca Mountain project are described in 10 CFR Part 63. The only citation in this regulation that specifically addresses criticality safety is:

Requirements for preclosure safety analysis of the geologic repository operations area; The preclosure safety analysis of the geologic repository operations area must include an analysis of the performance of the structures, systems, and components to identify those that are important to safety. This analysis identifies and describes the controls that are relied on to limit or prevent potential event sequences or mitigate their consequences. This analysis also identifies measures taken to ensure the availability of safety systems. The analysis required in this paragraph must include, but not necessarily be limited to, consideration of means to prevent and control criticality (10 CFR 63.112 [e][6]).

Project requirements relating to criticality safety are described in Project Requirements Document (Canori and Leitner 2003) and Project Functional and Operational Requirements (Curry 2004). These requirements are not detailed here, but this report's applications refer to appropriate preclosure project requirements.

\subsection{CRITICALITY CONTROL CRITERIA AND GUIDANCE}

Since the regulatory requirements of 10 CFR 63.112 [e][6] are not detailed, it is useful to describe the general design criteria, NRC guidance, analysis methods and computer codes, events, operations, and other considerations that will be used to guide the design approach for criticality analyses. This section focuses on the guidance that will be used to implement the requirements of $10 \mathrm{CFR} 63.112[\mathrm{e}][6]$. 


\subsubsection{General Design Criteria}

The general guidance used for waste form storage and handling is to confirm that analyses used to identify SSCs important to safety, safety controls, and measures to ensure the availability of the safety systems include adequate consideration of means to prevent or control criticality, such as complying with American National Standards Institute (ANSI)/American Nuclear Society (ANS) nuclear criticality safety standard documents listed in Regulatory Guide 3.71 (1998). The standards applicable to nuclear criticality safety are listed in Section 2.2.3. The term "waste form" will be applied to the canistered or uncanistered form (e.g., commercial fuel assembly).

According to Appendix A of 10 CFR Part 50, General Design Criterion 62, the primary design criterion for prevention of criticality in fuel storage and handling is as follows:

Criticality in the fuel storage and handling system shall be prevented by physical systems or processes, preferably by use of geometrically safe configurations.

This criterion has been used in recent license applications for multiregion spent nuclear fuel storage racks, checkerboard-loading patterns for spent nuclear fuel storage, credit for burnup, and credit for nonremovable poison inserts (Kopp 1998). It applies to the waste forms in the scope of this report.

Additional project design criteria applicable to criticality safety will also be met.

\subsubsection{NRC Guidance}

Guidance from the NRC pertaining to nuclear criticality safety analysis is contained in several technical documents issued by the NRC or under NRC direction. They include Regulatory Guides, Interim Staff Guidance documents, as well as those issued by the NRC directly (NUREG series) or by their contractors (NUREG/CR series). Those applicable to the preclosure criticality analysis process are listed in Table 1. 
Table 1. NRC Guidance Document Applicability

\begin{tabular}{|c|c|c|}
\hline Guidance Document & Applicability & Description \\
\hline $\begin{array}{l}\text { Regulatory Guide } 3.60 \text { (1987), Design of } \\
\text { an Independent Spent Fuel Storage } \\
\text { Installation (Dry Storage) }\end{array}$ & Out-of-package & $\begin{array}{l}\text { Supports issues regarding criticality safety for } \\
\text { fuel staging area and surface aging facility. }\end{array}$ \\
\hline $\begin{array}{l}\text { Regulatory Guide } 3.71 \text { (1998), Nuclear } \\
\text { Criticality Safety Standards for Fuels and } \\
\text { Material Facilities }\end{array}$ & $\begin{array}{l}\text { Out-of-package } \\
\text { and in-package }\end{array}$ & $\begin{array}{l}\text { Acceptance and exceptions to the ANSI/ANS } \\
\text { standards in Section } 2.2 .3 \text { are noted. }\end{array}$ \\
\hline $\begin{array}{l}\text { ISG-1, Revision } 1 \text { (NRC 2002c), } \\
\text { Damaged Fuel }\end{array}$ & $\begin{array}{l}\text { Out-of-package } \\
\text { and in-package }\end{array}$ & $\begin{array}{l}\text { Includes a definition of damaged fuel and } \\
\text { describes requirements for nuclear criticality } \\
\text { safety analysis of damaged fuel. }\end{array}$ \\
\hline $\begin{array}{l}\text { ISG-8, Revision } 2 \text { (NRC 2002b), Burnup } \\
\text { Credit in the Criticality Safety Analyses of } \\
\text { PWR Spent Fuel in Transport and Storage } \\
\text { Casks }\end{array}$ & In-package & $\begin{array}{l}\text { This guidance includes information regarding } \\
\text { the use of burnup credit. }\end{array}$ \\
\hline $\begin{array}{l}\text { ISG-11, Revision } 2 \text { (NRC 2002d), } \\
\text { Cladding Considerations for the } \\
\text { Transportation and Storage of Spent Fuel }\end{array}$ & $\begin{array}{l}\text { Out-of-package } \\
\text { and in-package }\end{array}$ & $\begin{array}{l}\text { Describes the potential reconfiguration of fuel } \\
\text { during storage operations as related to creep } \\
\text { and temperature effects. }\end{array}$ \\
\hline ISG-15 (NRC 2001), Materials Evaluation & $\begin{array}{l}\text { Out-of-package } \\
\text { and in-package }\end{array}$ & $\begin{array}{l}\text { This guidance includes information regarding } \\
\text { the use of neutron absorbing/poison materials } \\
\text { for criticality control. }\end{array}$ \\
\hline $\begin{array}{l}\text { NRC Letter (Kopp 1998), "Guidance on } \\
\text { the Regulatory Requirements for Criticality } \\
\text { Analysis of Fuel Storage at Light-Water } \\
\text { Reactor Power Plants" }\end{array}$ & $\begin{array}{l}\text { Out-of-package } \\
\text { and in-package }\end{array}$ & $\begin{array}{l}\text { Although directed at nuclear power plants, } \\
\text { this guidance is useful to the Yucca Mountain } \\
\text { Project because it includes several } \\
\text { clarifications and documents the current NRC } \\
\text { positions regarding the storage of SNF. }\end{array}$ \\
\hline $\begin{array}{l}\text { NUREG-1536 (NRC 1997), Standard } \\
\text { Review Plan for Dry Cask Storage } \\
\text { Systems (Section 6) }\end{array}$ & $\begin{array}{l}\text { Out-of-package } \\
\text { and in-package }\end{array}$ & $\begin{array}{l}\text { This guidance includes information regarding } \\
\text { criticality design and analysis related to spent } \\
\text { nuclear fuel handling, packaging, transfer, } \\
\text { and storage procedures for normal, off- } \\
\text { normal, and accident conditions as pertaining } \\
\text { to } 10 \text { CFR Part } 72 \text {. }\end{array}$ \\
\hline $\begin{array}{l}\text { NUREG-1567 (NRC 2000, Sections } \\
\text { 4.4.3.5, 4.5.3.5, and 8), Standard Review } \\
\text { Plan for Spent Fuel Dry Storage Facilities }\end{array}$ & Out-of-package & $\begin{array}{l}\text { This guidance includes information regarding } \\
\text { stored materials remaining subcritical under } \\
\text { normal, off-normal, and accident conditions } \\
\text { during all operations, transfers, and storage } \\
\text { at the site as pertaining to } 10 \text { CFR Part } 72 \text {. }\end{array}$ \\
\hline $\begin{array}{l}\text { NUREG-1804 (NRC 2003), Yucca } \\
\text { Mountain Review Plan, Final Report } \\
\text { (Various sections) }\end{array}$ & $\begin{array}{l}\text { Out-of-package } \\
\text { and in-package }\end{array}$ & $\begin{array}{l}\text { This guidance is the review plan for the } \\
\text { Yucca Mountain project and pertains to } \\
10 \text { CFR Part } 63 \text {. }\end{array}$ \\
\hline $\begin{array}{l}\text { NUREG/CR-6361 (Lichtenwalter et al. } \\
\text { 1997), Criticality Benchmark Guide for } \\
\text { Light-Water-Reactor Fuel in } \\
\text { Transportation and Storage Packages }\end{array}$ & $\begin{array}{l}\text { Out-of-package } \\
\text { and in-package }\end{array}$ & $\begin{array}{l}\text { This guidance includes information regarding } \\
\text { benchmark experiment selection process and } \\
\text { methods for calculating critical limits. }\end{array}$ \\
\hline $\begin{array}{l}\text { NUREG-1520 (NRC 2002a, Section 5), } \\
\text { Standard Review Plan for the Review of a } \\
\text { License Application (LA) for a Fuel Cycle } \\
\text { Facility }\end{array}$ & $\begin{array}{l}\text { Out-of-package } \\
\text { and in-package }\end{array}$ & $\begin{array}{l}\text { This guidance includes information regarding } \\
\text { nuclear criticality safety to support safe } \\
\text { operation of the facility, as required by } \\
10 \text { CFR Part } 70 \text {. }\end{array}$ \\
\hline
\end{tabular}


Although not directly applicable to the Yucca Mountain Project, 10 CFR Part 72 provides a more detailed list of regulations relating to criticality safety, which will be used for general guidance. The portion that specifically addresses criticality safety, which provides guidance for out-ofpackage operations, is noted in 10 CFR 72.124 , which states:

(a) Design for criticality safety. Spent fuel handling, packaging, transfer, and storage systems must be designed to be maintained subcritical and to ensure that, before a nuclear criticality accident is possible, at least two unlikely, independent, and concurrent or sequential changes have occurred in the conditions essential to nuclear criticality safety. The design of handling, packaging, transfer, and storage systems must include margins of safety for the nuclear criticality parameters that are commensurate with the uncertainties in the data and methods used in calculations and demonstrate safety for the handling, packaging, transfer and storage conditions and in the nature of the immediate environment under accident conditions.

(b) Methods of criticality control. When practicable, the design of an ISFSI [independent spent fuel storage installation] or MRS [monitored retrievable storage] must be based on favorable geometry, permanently fixed neutron absorbing materials (poisons), or both. Where solid neutron absorbing materials are used, the design must provide for positive means of verifying their continued efficacy. For dry spent fuel storage systems, the continued efficacy may be confirmed by a demonstration or analysis before use, showing that a significant degradation of the neutron absorbing materials cannot occur over the life of the facility.

Out-of-package criticality analysis includes the evaluation of processes starting with the receipt of transportation casks and includes everything up to the loading of waste packages for closure and emplacement in the subsurface. In-package criticality analysis includes the evaluation of processes starting with the loading of waste packages for closure and emplacement and continuing until the time of permanent closure.

The guidance provided in NUREG-1520 (NRC 2002a, Section 5), for criticality safety analysis, provides insight into the NRC's approach to risk-informed regulation of spent nuclear fuel handling and storage facilities. Criticality control in the carrier/cask handling system is largely provided by transportation casks designed and licensed in accordance with requirements in 10 CFR Part 71, Packaging and Transportation of Radioactive Material, and by spent nuclear fuel loading procedures implemented at the transportation cask's point of origin.

The guidance from Guidance on the Regulatory Requirements for Criticality Analysis of Fuel Storage at Light-Water Reactor Power Plants (Kopp 1998) was intended for commercial spent nuclear fuel; however, it is being applied for waste forms listed in this report, unless indicated differently. This guidance comes from the NRC Reactor Systems Branch and is used in assuring criticality safety in the storage of new and spent nuclear fuel at light-water reactor power stations. 
The following guidance from Kopp (1998) is applicable to CSNF (pressurized water reactor [PWR] and boiling water reactor [BWR] spent nuclear fuel).

Preclosure criticality analyses will use a bounding model and parameters, which will result in a more reactive state than the actual or real state. Sensitivity studies will be performed to ensure that a bounding representation is used. The determination of the effective neutron multiplication factor $\left(\mathrm{k}_{\mathrm{eff}}\right)$ for CSNF will consider the following:

A. Fuel rod parameters, including:

1. Fuel pellet diameter

2. Cladding material and inner and outer diameters

3. Fuel rod pellet or stack density and initial fissile enrichment of each fuel rod in the assembly (a bounding enrichment is acceptable)

4. Active fuel height.

B. Fuel assembly parameters, including:

1. Assembly length and planar dimensions

2. Fuel rod pitch

3. Total number of fuel rods in the assembly

4. Locations in the fuel assembly lattice that are empty or contain nonfuel material (e.g., guide tubes, burnable poison rods)

5. Integral neutron absorber (burnable poison) content of various fuel rods and locations in fuel assembly. This is typically proprietary information and may not be available. For out-of-package operations no credit will be taken for the presence of integral absorbers. For in-package operations, no credit will be taken for residual integral absorbers in the fuel.

6. Structural materials (e.g., grids) that are an integral part of the fuel assembly.

Similar considerations on geometry and material concentrations will be used for the other waste forms (e.g., DOE SNF), both in-package and out-of-package, in the scope of this report. These considerations will also focus on the geometry and material concentrations of the waste forms.

For CSNF, the criticality safety analyses will use a bounding approach for the treatment of axial and planar variations of fuel assembly characteristics, such as fuel enrichment and integral neutron absorber if present (e.g., gadolinia $\left(\mathrm{Gd}_{2} \mathrm{O}_{3}\right)$ in certain fuel rods of BWR and PWR assemblies or integral fuel burnable absorber coatings in certain fuel rods of PWR assemblies, or gadolinia in plutonium). The latter characteristics should only be required if it is intended to take credit for the presence of these materials; however, they may be required if burnup credit is taken 
for in-package operations. The bounding approach used for axial variations will be to use the maximum initial enrichment at each axial level, and planar variations will be bounded by not taking credit for integral neutron absorbers. When burnup credit is taken, the spent nuclear fuel isotope concentrations will be generated using the isotopic model (BSC 2004d), which will provide conservative spent nuclear fuel isotope concentrations with respect to criticality safety applications. For waste forms other than CSNF, credit for integral absorbers can be used if there are no mechanisms that remove the absorber during preclosure.

Whenever reactivity equivalencing (i.e., burnup credit or credit for imbedded burnable absorbers) is employed, or if a correlation with the reactivity of commercial fuel assemblies in standard core geometry is used, the equivalent reactivities must be evaluated in the waste package configuration (out-of-package operations will not use reactivity equivalencing). Sufficient margin will be incorporated into the calculated $\mathrm{k}_{\text {eff }}$ values to account for the reactivity effects of the following:

- Nonuniform enrichment variation (this will be handled by using the maximum enrichment over the whole assembly length)

- Uncertainty in the calculation of $\mathrm{k}_{\mathrm{eff}}$ (bias and uncertainty determined from benchmark calculations)

- Uncertainty in average enrichment (this will be handled by using the maximum enrichment over the whole assembly length).

If criticality safety relies on administrative controls, these controls will be explicitly identified and implemented in operating procedures and/or technical specification limits.

\subsubsection{Standards}

Several standards have been identified by the NRC in Regulatory Guide 3.71 (1998) as being applicable to nuclear criticality safety. These have also been cited in various NUREG documents relating to nuclear criticality safety, including NUREG-1520, -1567, and -1804 (NRC 2002a, Section 5; NRC 2000, Sections 4.4.3.5, 4.5.3.5, and 8; and NRC 2003) and are as follows:

- ANSI/ANS-8.1-1983. Nuclear Criticality Safety in Operations with Fissionable Materials Outside Reactors.

- ANSI/ANS-8.3-1997. Criticality Accident Alarm System.

- ANSI/ANS-8.5-1996. Use of Borosilicate-Glass Raschig Rings as Neutron Absorber in Solutions of Fissile Material.

- ANSI/ANS-8.7-1998. 1999. American National Standard for Nuclear Criticality Safety in the Storage of Fissile Materials.

- ANSI/ANS-8.10-1983. Criteria for Nuclear Criticality Safety Controls in Operations with Shielding and Confinement. 
- ANSI/ANS-8.12-1987. American National Standard for Nuclear Criticality Control and Safety of Plutonium-Uranium Fuel Mixtures Outside Reactors.

- ANSI/ANS-8.15-1981. Nuclear Criticality Control of Special Actinide Elements.

- ANSI/ANS-8.17-1984. Criticality Safety Criteria for the Handling, Storage, and Transportation of LWR Fuel Outside Reactors.

- ANSI/ANS-8.19-1996. American National Standard, Administrative Practices for Nuclear Criticality Safety.

- ANSI/ANS-8.21-1995. American National Standard for the Use of Fixed Neutron Absorbers in Nuclear Facilities Outside Reactors.

- ANSI/ANS-8.22-1997. American National Standard for Nuclear Criticality Safety Based on Limiting and Controlling Moderators.

The following provides a listing of exceptions to parts of the recommended standard documents and guidance from Regulatory Guide 3.71 (1998):

1. Exceptions are taken with portions of the recommended ANSI/ANS-8 nuclear criticality safety standards that are being used.

a. The double contingency principle is not applied since it is expanded on and subsumed in the risk-informed, performance-based approach from 10 CFR Part 63. The double contingency approach typically evaluates event sequences until at least two unlikely, independent, and concurrent changes in process conditions are required before a criticality accident is possible. The risk-informed approach uses Probabilistic Risk Assessment to calculate probabilities of events with potential public health consequences and the magnitudes of these potential health consequences, so that an entire event sequence is evaluated from initiation to conclusion, including event sequences which may have been otherwise terminated by a double contingency approach.

b. Use of single parameter limits for aqueous solutions, aqueous mixtures, metallic units, and oxides of fissile material described that are not scheduled for disposal at the repository.

c. Use of multiparameter control for systems of fissile material described that are not scheduled for disposal at the repository.

2. An exception is being made to the requirement in Regulatory Guide 3.71 (1998) that criticality alarm systems be present in each area where special nuclear material is handled, used, or stored. Criticality accident alarm systems will not be used in repository facilities provided an adequate demonstration is made to show that the dose consequence to personnel locations is less than $0.12 \mathrm{gray} / 12 \mathrm{rads}$ (ANSI/ANS-8.31997, Section 3.3) or, the probability of criticality is beyond a Category 2 event sequence. 
3. Additional physical measurements of burnup are not performed for CSNF assemblies. The burnup values used for burnup credit purposes will be based on reactor records and process knowledge, with allowance made for uncertainty in the burnup values from the records. The records are more accurate than the physical measurements performed outside a reactor. Physical measurements of burnup will not be performed for the other waste forms either since a fresh fuel assumption with no burnup credit is used for nonbreeder reactor fuel, and calculated most reactive state, is used for breeder reactor fuel.

\subsubsection{Criticality Analysis Methods and Computer Codes}

The MCNP (Briesmeister 1997) computer code will be used for the criticality analyses. The Monte Carlo computational method is discussed in the Criticality Model (BSC 2004c, Section 6.1) and briefly summarized in Section 3.3 of this report. As noted below, the analysis method embodied in this code will be benchmarked by comparison with experiments. However, if further confirmation is needed, Kopp (1998, p. 3) recommends the primary method of analysis be verified by a second, independent method of analysis. According to Kopp (1998, p. 3) acceptable computer codes include, but are not necessarily limited to, the following:

- CASMO-A multigroup transport theory code in two dimensions

- NITAWL-KENO5a-A multigroup transport theory code in three dimensions, using the Monte Carlo technique

- PHOENIX-P or DOT-A multigroup transport theory code in two dimensions, using discrete ordinate

- MONK6B-A multigroup transport theory code in three dimensions, using the Monte Carlo technique.

These codes are not currently used on the Yucca Mountain Project, and would have to be qualified if used in the future.

The proposed analysis methods and neutron cross-section data will be benchmarked by comparison with critical experiments. This qualifies the application and the computer environment. The critical experiments used for benchmarking will include, to the extent possible, configurations having neutronic and geometric characteristics similar to those of the proposed system. As it is released, the latest version of International Handbook of Evaluated Criticality Safety Benchmark Experiments (NEA 2001) will be the primary benchmark experiment reference. Commercial reactor critical (CRC) systems will also be used in benchmarking for in-package operations. A comparison with methods of analysis of similar sophistication (e.g., transport theory) may be used to augment or extend the range of applicable critical experiment data.

The benchmarking analysis will establish both a bias (defined as the mean difference between experimental and calculated values) and uncertainty of the mean with a one-sided tolerance 
factor for 95 percent probability at the 95 percent confidence level (Kopp 1998, pp. 3 and 4). The maximum $\mathrm{k}_{\mathrm{eff}}$ shall be evaluated from the following expression:

$$
\mathrm{k}_{\mathrm{eff}}=\mathrm{k}(\text { calc })+\Delta \mathrm{k}(\text { uncert })+\Delta \mathrm{k} \text { (burnup) }
$$

where

$$
\begin{array}{ll}
\mathrm{k}(\text { calc })= & \text { calculated nominal value of } \mathrm{k}_{\text {eff }} \\
\Delta \mathrm{k}(\text { uncert })= & \text { manufacturing and calculational bias and uncertainties } \\
\Delta \mathrm{k} \text { (burnup) }= & \begin{array}{l}
\text { correction for the effect of the axial distribution in burnup when credit } \\
\text { for burnup is taken (Note: provisions for the uncertainty in the average } \\
\text { burnup of a fuel assembly must also be made in the loading criteria) }
\end{array}
\end{array}
$$

Use of the last term, $\Delta \mathrm{k}$ (burnup), is not applicable to out-of-package applications and may be obviated for in-package applications by use of the design constraints for postclosure criticality analysis (YMP 2003). The uncertainty associated with a SNF assembly's assigned burnup value is accounted for by adjusting the minimum required burnup, as a function of enrichment, upward by the uncertainty associated with the assigned assembly average burnup values.

A bias that would reduce the calculated value of $k_{\text {eff }}$ will not be applied to ensure calculations will always be conservative. Uncertainties should be determined for the system to account for tolerances in the mechanical and material specifications. An acceptable method for determining the maximum reactivity may be either: (1) a worst-case combination with mechanical and material conditions set to maximize $k_{\text {eff, }}$ or (2) a sensitivity study of the reactivity effects of tolerance variations.

If used, a sensitivity study should include all possible significant variations (tolerances) in the material and mechanical specifications of the storage racks and waste packages including fuel assembly bowing and crud build-up on the rods. The results may be combined statistically, provided they are independent variables.

Classification of SNF and high-level waste from commercial and DOE sources will be performed in order to economize in the number of criticality cases that must be considered. This is accomplished by reducing the many different types of SNF and high-level radioactive waste to as few as possible bounding types. From these classifications, a reduced set of groupings will be defined according to those that result in greatest reactivity conditions based on parametric studies.

\subsubsection{Initiating Events and Event Sequences}

Criticality safety analyses will consider event sequences related to criticality. An analysis of the performance of the SSCs to identify those that are important to safety will be performed. This analysis will identify and describe the controls that are relied on to limit or prevent potential event sequences or mitigate their consequences. This analysis will consider means to prevent and control criticality, and to identify measures taken to ensure safety systems availability. 


\subsubsection{In-Package Operations}

Dry waste forms are transferred into waste packages and then into the repository. However, moderator may be introduced into the system under abnormal situations, such as flooding or the introduction of foam, water mist (e.g., a result of fire fighting operations), or oil (e.g., hydraulic fluids). Optimum moderation is the level at which peak reactivity occurs. Because, in the case of foam or mist, the peak reactivity may occur at less than full-density water $\left(1.0 \mathrm{~g} / \mathrm{cm}^{3}\right)$, sensitivity studies will be conducted to determine the optimum moderation condition and its associated $\mathrm{k}_{\text {eff. }}$ Therefore, criticality safety analyses must address one of two conditions that should be incorporated into facility technical specifications. The second condition needs to be incorporated only in the event a waste package is determined to be overmoderated. The two conditions follow:

- With the waste package loaded with waste of the maximum permissible reactivity and flooded with pure water, the maximum $\mathrm{k}_{\mathrm{eff}}$ shall be no greater than 0.95 (Kopp 1998, p. 5), including mechanical and calculational uncertainties, with a 95-percent probability at a 95-percent confidence level.

- With the waste package loaded with waste of the maximum permissible reactivity and flooded with moderator at the (low) density corresponding to optimum moderation, the maximum $\mathrm{k}_{\text {eff }}$ shall be no greater than 0.98 (Kopp 1998, p. 5), including mechanical and calculational uncertainties, with a 95-percent probability at a 95-percent confidence level.

An evaluation need not be performed for the waste package flooded with low-density or full-density water if it can be clearly demonstrated that design features prevent such flooding (Kopp 1998, p. 5).

The waste package may be designed with lattice controls (e.g., large lattice spacing or mechanically blocked lattice positions) sufficient to maintain a low reactivity under the accident condition of flooding. In the evaluation of the waste package, waste form and system characteristics upon which subcriticality depends will be explicitly identified (e.g., the presence of steel plates or other structures). The waste package should be designed to contain the most reactive waste form to be stored without taking credit for any nonfixed neutron absorber.

\subsubsection{Out-of-Package Operations}

Spent nuclear fuel assemblies may be stored in dry storage racks with off-normal assemblies being stored in a pool if necessary. For each storage configuration the following processes will be used in performing the out-of-package criticality calculations:

1. Design of facilities will be based on most reactive fuel assemblies.

2. The effective neutron multiplication factor $\left(\mathrm{k}_{\mathrm{eff}}\right)$, including all biases and uncertainties at a 95-percent confidence level, will not exceed 0.95 under all credible normal, offnormal, and accident conditions (NRC 2000, Section 8.4.1.1). The latter two conditions are inclusive of Category 1 and 2 event sequences as defined in 
10 CFR 63.2. If bias is positive for any variable, a value of 0.0 will be assigned for | that variable in the overall determination.

3. Criticality modeling will use conservative assumptions leading to maximum reactivity for all dimensional variables including:
A. Pitch for fuel assemblies and canisters
B. Manufacturing tolerances for assemblies, canisters, storage racks, etc.

4. Criticality modeling will use conservative assumptions regarding materials in fuel including but not limited to:
A. No burnable poisons will be accounted for in fuel.
B. No credit will be taken for ${ }^{234} U$ or ${ }^{236} U$ in fuel.
C. No credit will be taken for fission product or transuranic absorbers in fuel.
D. Most reactive fuel stack density will be assumed.

5. For fixed neutron absorbers used for criticality control such as grid plates or inserts, no more than 75 percent (NRC 2000, Section 8.4.1.1) credit of the neutron absorber content is used for preclosure criticality analyses, unless standard acceptance tests verify that the presence and uniformity of the neutron absorber are more effective.

6. The design of storage racks in the pool located in the remediation facility will be based on excluding soluble boron for criticality control.

7. Consideration will be given to extensions of important data variables such as quantity and density of moderator. For any moderator present (e.g., water, foam, oil), appropriate ranges of quantity and density will be examined. This will ensure optimum moderation conditions will be considered.

8. Consideration will be given to potential reflectors during transfer and placement.

\subsubsection{Additional Considerations}

Although not strictly part of the process of calculating $\mathrm{k}_{\mathrm{eff}}$, the following additional considerations may apply to determination of design configurations or event sequences. The first four items apply to in-package or out-of-package operations. The last two items apply to inpackage operations.

1. The analysis must consider the effect on criticality of natural events (e.g., earthquakes) or incidents (e.g., dropped assembly) that may deform or change the relative position of the storage configuration or the waste package. 
2. Normally, credit may only be taken for neutron absorbers that are an integral (nonremovable) part of the system. Credit for added absorber (rods, plates, or other configurations) will be considered on a case-by-case basis, provided it can be clearly demonstrated that design features prevent the absorbers from being removed, either inadvertently or intentionally without unusual effort, such as the necessity for special equipment maintained under administrative control.

3. Consolidated fuel assemblies usually result in low values of reactivity (undermoderated lattice, which results in less effective neutron thermalization). Nevertheless, criticality calculations, using an explicit geometric description (usually triangular pitch) or as near an explicit description as possible, should be performed to assure a $\mathrm{k}_{\text {eff }}$ less than 0.95 . This option may be applied for off-nominal assembly types.

4. Evaluation of fabrication errors for canister, waste packages, and storage racks.

5. Misloading of waste form in the waste package must be considered. Normally, a misloading error involving more than a single unit need not be considered unless there are circumstances that make multiloading errors credible.

6. Although the surface facilities are not in the final design phase, it is expected that waste packages, once loaded, will be kept in separate handling lines such that package-topackage interaction is unlikely. Once the waste package is sealed, the introduction of moderator into the package is not probable; therefore, even if packages were placed next to each other, the spacing between assemblies within the packages provides sufficient neutronic decoupling. Nevertheless, sensitivity calculations should be performed to demonstrate that waste packages will not interact with each other, from a neutronics standpoint. 


\section{CRITICALITY ANALYSIS}

Criticality evaluations are performed for configurations from event sequences or design configurations over the range of parameters established based on pertinent characteristics (e.g., geometric arrangement). In-package and out-of-package configurations that may have the potential for criticality are considered.

An overview of the preclosure criticality analysis process is presented in Figure 1. This process is described in Sections 3.1 through 3.5, as outlined below.

Section 3.1 describes the identification of event sequences and design configurations requiring criticality evaluations. This includes establishment of the range of parameters for the event sequences and design configurations, specifically the materials of the waste package and waste form, the geometry of the waste package and waste form, and the neutron energy spectrum affecting fissionable materials.

Section 3.2 discusses waste form characteristics, i.e., isotopic concentrations, including use of burnup credit for in-package evaluations of commercial spent nuclear fuel (CSNF).

Section 3.3 summarizes the calculation of $\mathrm{k}_{\mathrm{eff}}$ using the Criticality Model (BSC 2004c).

Section 3.4 describes validation, including determination and application of an upper subcritical limit (USL). The USL is an upper limit placed on $\mathrm{k}_{\mathrm{eff}}$ to ensure subcriticality with allowances made for the bias and uncertainty in the calculation model, as well as an arbitrary administrative criticality safety margin. Determination of the USL includes (1) selection of appropriate benchmark experiments, (2) establishment of the range of applicability of those experiments, (3) establishment of a lower-bound tolerance limit, and, if necessary, (4) establishment of any penalties for extending the range of applicability.

Section 3.5 discusses the USL criterion.

Finally, Section 3.6 discusses the application of the preclosure criticality analysis process. 


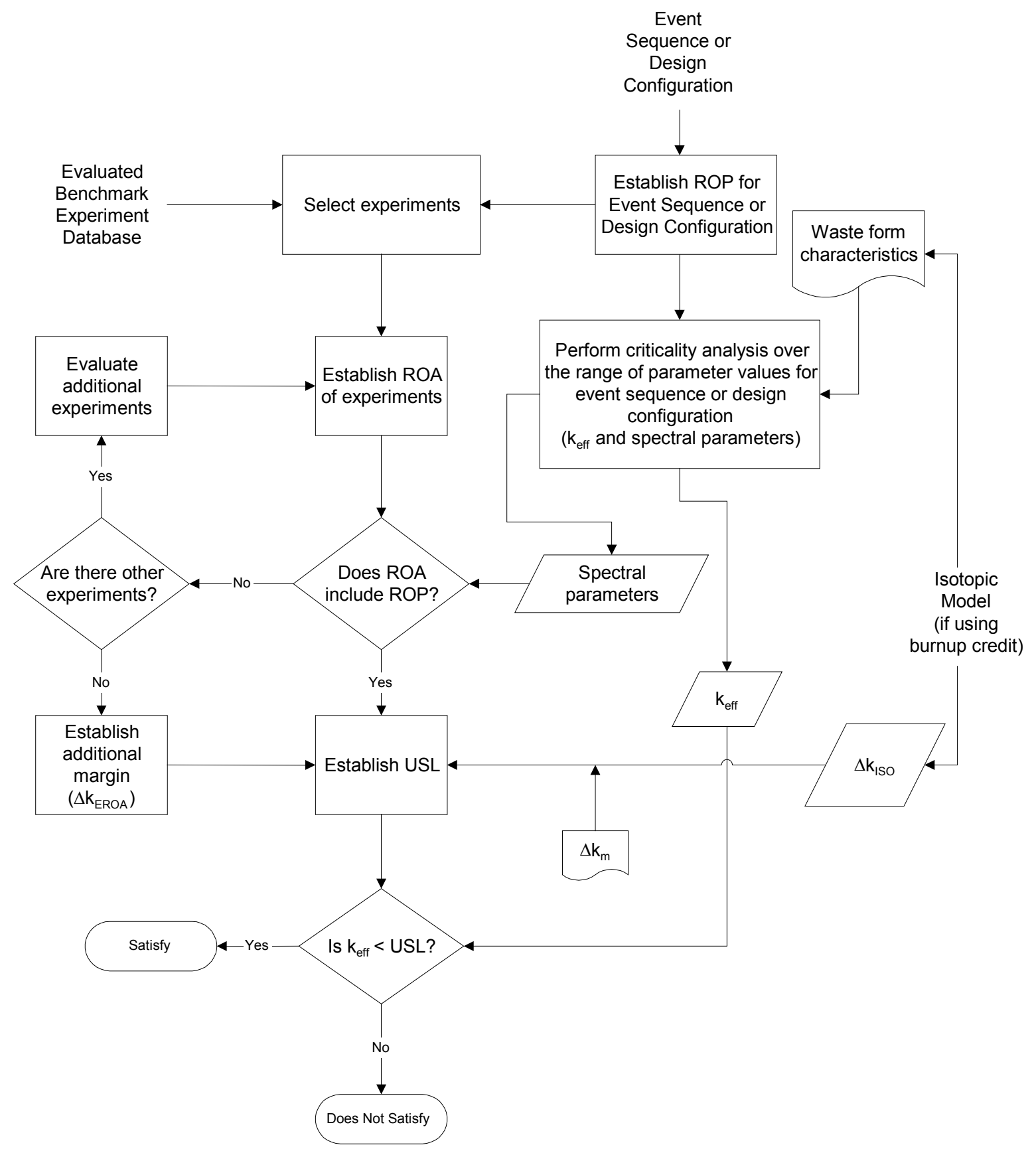

NOTES: $\triangle K_{E R O A}=$ penalty for extending the range of applicability

$\Delta \mathrm{k}_{\text {ISO }}=$ penalty for isotopic composition bias and uncertainty for burnup credit

$\Delta \mathrm{k}_{\mathrm{m}} \quad=$ an arbitrary margin ensuring subcriticality for preclosure

Figure 1. Preclosure Criticality Analysis Process Overview

\subsection{IDENTIFICATION OF CRITICALITY EVENT SEQUENCES AND DESIGN CONFIGURATIONS}

Criticality event sequences are a series of actions, occurrences, or both within the repository operations area that could potentially lead to a criticality event. An event sequence may include 
one or more initiating events and any associated number of combinations of system component failures, including those produced by operating personnel action or inaction. Those event sequences expected to occur one or more times before permanent closure of the repository are referred to as Category-1 event sequences. Those with at least one chance in 10,000 of occurring before permanent closure are referred to as Category-2 (10 CFR 63.2).

Criticality safety standards require the $\mathrm{k}_{\mathrm{eff}}$ of the system being evaluated be maintained below unity (1.0), after allowance for bias and uncertainty in the method of calculation and any administrative margin imposed during all Category-1 and Category-2 event sequences. Hazards considered incredible (i.e., that could initiate neither a Category-1 or Category-2 event sequence) would be identified, but will not require evaluation in the preclosure safety analysis.

The event sequences to be considered as part of the criticality safety analysis are identified as part of preclosure safety analysis. Event sequences must be determined through review of the facility design. Reviews to identify and categorize such events have been previously identified in Categorization of Event Sequences for License Application (BSC 2004e, Section 7). However, the list of event sequences provided in this categorization is not specific to criticality safety. For the criticality safety portion of the preclosure safety analysis, otherwise benign events must also be considered. These include events that may result in unanticipated moderation (e.g., activation of sprinkler systems, introduction of hydrogenous fluids from failed hydraulic cylinders or oil systems), formation of unanticipated geometries (e.g., drop events), or administrative errors in waste form placement (e.g., misloads [BSC 2003a]).

Design configurations are identified during the design process for the surface facilities and the waste packages. Criticality evaluations of these configurations, e.g., spacing of CSNF assemblies in storage racks or determination of absorber plate materials for a waste package, are performed as part of the design process.

Given an event sequence from a hazards analysis or a design configuration to be evaluated, the appropriate range of parameters representing the material composition and geometry is determined. Specifically, there are three fundamental areas (Lichtenwalter et al. 1997, p. 179) to be considered: (1) materials of the waste package and waste form, especially fissionable materials, (2) geometry of the waste package and waste forms, and (3) the inherent neutron energy spectrum affecting fissionable materials. For example, these could include the range of initial enrichments of the CSNF, the thickness of absorber plates in a waste package, the spacings of assemblies in a storage rack, and neutronic parameters such as the $\mathrm{H} / \mathrm{X}$ ratio and the neutron spectrum.

\subsection{WASTE FORM CHARACTERISTICS}

The approach for modeling isotopic concentrations from the waste forms applicable to preclosure is described by a two-step process (BSC 2004d). First, the initial isotopic concentrations of the waste form at the time of emplacement in the repository are established. Second, the changes in isotopic concentrations resulting from isotopic decay are calculated.

For each waste form type, design values for fissionable isotopic concentrations or technical specification limits for fissile isotope concentrations will be used in establishing the initial 
isotopic content of the waste form. When fissile isotope production during reactor operations leads to a higher reactivity (e.g., breeder fuel), adjustments will be made to the design values to account for the increase in fissile isotopic content. For in-package operations, the isotopic concentrations will then be adjusted to account for isotopic decay until the time of the potential criticality or a time that provides more conservative isotopic concentrations. This modeling approach for these waste forms must be confirmed to be conservative with respect to criticality.

\subsubsection{Fresh or Most-Reactive Fuel}

Out-of-package evaluations for all waste forms and in-package evaluations for DOE SNF and high-level waste will use the most reactive fuel state (i.e., fresh fuel assumption with no burnup credit for nonbreeder reactor fuel, or calculated most reactive state for breeder reactor fuel). The in-package operations will include credit for burnup for CSNF similar to the postclosure methodology (YMP 2003).

\subsubsection{Isotopic Model for CSNF Burnup Credit}

For CSNF, the reduced reactivity associated with the net depletion of fissile isotopes and the creation of neutron-absorbing isotopes during the period since the fuel was first inserted into a commercial reactor can reduce the criticality potential of CSNF configurations. This period includes the irradiation time of the fuel in a reactor, the downtime between irradiation cycles, and the cooling time since the fuel was removed from the reactor. Taking credit for the reduced reactivity associated with this change in fuel material composition is known as burnup credit. This credit is taken only for in-package evaluations for CSNF. The isotopic model (BSC 2004d) determines the concentrations of the isotopes that are present in the CSNF and subsequently used in the in-package criticality evaluations.

Typically, an assembly's reported burnup values are averages, which underestimate burnup at the center of the assembly and overestimate burnup at the top and the bottom. As fuel is burned in a reactor, the fuel burnup distributes axially and fuel reactivity decreases. To adequately use burnup credit, axial effects must be understood. This requires that an estimate of the reactivity effects of the axial burnup distribution relative to uniform distribution must be determined and appropriately applied to the results. This is discussed in Section 3.2.3. Alternatively, the explicit axial distribution can be modeled in the $\mathrm{k}_{\text {eff }}$ calculation, which removes the need for application of an axial burnup penalty.

Radiochemical assay data can be used in conjunction with CRC data to validate the isotopic model (BSC 2004d). The CRC data addresses the integral contribution of isotopic concentrations to criticality. Radiochemical assay data provide measured concentrations for individual isotopes. Conservative calculations of isotopic concentrations are ensured by choosing bounding parameters for the fuel irradiation. A comparison of the $\mathrm{k}_{\mathrm{eff}}$ for nominal parameter values and bounding values are performed to determine the magnitude of conservatism caused by the use of bounding values.

The following discussion compares licensing approaches for obtaining burnup credit for CSNF in commercial reactor spent nuclear fuel pools and for a waste package during preclosure at 
Yucca Mountain. The purpose of this comparison is to demonstrate the similarities between $\mathrm{NRC}$ accepted industry practices and the project approach.

The basis for the statements on the proposed approach for the waste package is Disposal Criticality Analysis Methodology Topical Report (YMP 2003). The basis for the statements on licensing practices used for burnup credit at spent nuclear fuel pools are provided in "Guidance on the Regulatory Requirements for Criticality Analysis of Fuel Storage at Light-Water Reactor Power Plants" (Kopp 1998) and Rochester Gas and Electric Corporation, Docket No. 50-244, R.E. Ginna Nuclear Power Plant, Amendment to Facility Operating License (NRC 1998).

Spent nuclear fuel pools at reactor sites and preclosure conditions for a waste package are similar since (1) both involve the movement and storage of CSNF in a secured facility with no proximity to the public, and (2) both have multiple protective barriers against criticality or its consequences (e.g., geometric spacing, soluble or fixed absorbers, shielding). Consequently, the NRC can consider reductions in administrative margin-to-criticality for reactor sites (Kopp 1998, 4(b) p. 5, 2(a) p. 6).

Other similarities are as follows:

- Isotopic Calculations-Both use isotopic compositions from computer codes using the same basic equations. Calculations for pools and waste packages can both use one- or two-dimensional geometry.

- Criticality Calculations-Both use industry-accepted computer codes. The NRC has accepted the codes when used for spent nuclear fuel pools.

- Modeling of Axial Burnup Effects-Both use bounding axial shapes obtained from reactor experience.

- Loading Curves-The approach for the waste package (see the example in Appendix A) is identical to that for a spent nuclear fuel pool.

- Bias and Uncertainties-Both use a statistical approach defined in standards and regulatory guides.

- Validation of Criticality Calculations-Both use laboratory critical experiments (LCE). For the waste package, CRCs are used directly. The spent nuclear fuel pools use their commercial reactor experience indirectly; that is, the NRC recognizes licensees have reactor experience with their methods for determining burnup and isotopic content for reactivity calculations (NRC 1998, p.1 and Section 2.1.1).

- Risk Analysis- This is not necessarily related to burnup credit, although it could be (e.g., frequency of misloads based on loading restriction related to minimum burnup). For spent nuclear fuel pools, the current practice is to use the double-contingency principle, except the frequency of events is not necessarily determined. For the waste package, the proposed approach is to classify event sequences and show criticality is the result of an incredible event. 
The method to predict CSNF compositions for preclosure begins by calculating the isotopic concentrations of fissile and neutron-absorbing isotopes to be used for criticality evaluations. These calculations are based on conservative model input parameters, fuel-assembly burnup data, and fuel-assembly design data.

The criticality analysis model that will be applied for waste packages containing CSNF uses a subset of the isotopes present in the CSNF, which is consistent with the postclosure methodology (YMP 2003). The process for establishing the isotopes to be included is based on the nuclear, physical, and chemical properties. Nuclear properties considered are isotope cross-sections and half-lives (as applicable); physical properties are concentration (amount present in the SNF) and state (solid, liquid, or gas); and chemical properties are isotope volatility and solubility. Time effects (during disposal) and relative importance of isotopes for criticality (combination of crosssections and concentrations) are considered in this selection process. None of the isotopes with significant positive reactivity effects (fissionable isotopes) are removed from consideration, only nonfissionable absorbers are removed. Thus, the selection process is conservative.

This process results in selecting 14 actinides and 15 fission products (referred to as "principal isotopes" and listed in Table 2) as the SNF isotopes to be used for burnup credit (YMP 2003, Section 3.5.2.1.1).

Table 2. Principal Isotopes for CSNF Burnup Credit

\begin{tabular}{|c|c|c|c|c|}
\hline${ }^{95} \mathrm{Mo}$ & ${ }^{145} \mathrm{Nd}$ & ${ }^{151} \mathrm{Eu}$ & ${ }^{236} \mathrm{U}$ & ${ }^{241} \mathrm{Pu}$ \\
\hline${ }^{99} \mathrm{Tc}$ & ${ }^{147} \mathrm{Sm}$ & ${ }^{153} \mathrm{Eu}$ & ${ }^{238} \mathrm{U}$ & ${ }^{242} \mathrm{Pu}$ \\
\hline${ }^{101} \mathrm{Ru}$ & ${ }^{149} \mathrm{Sm}$ & ${ }^{155} \mathrm{Gd}$ & ${ }^{237} \mathrm{~Np}$ & ${ }^{241} \mathrm{Am}$ \\
\hline${ }^{103} \mathrm{Rh}$ & ${ }^{150} \mathrm{Sm}$ & ${ }^{233} \mathrm{U}$ & ${ }^{238} \mathrm{Pu}$ & ${ }^{242 \mathrm{~m}} \mathrm{Am}$ \\
\hline${ }^{109} \mathrm{Ag}$ & ${ }^{151} \mathrm{Sm}$ & ${ }^{234} \mathrm{U}$ & ${ }^{239} \mathrm{Pu}$ & ${ }^{243} \mathrm{Am}$ \\
\hline${ }^{143} \mathrm{Nd}$ & ${ }^{152} \mathrm{Sm}$ & ${ }^{235} \mathrm{U}$ & ${ }^{240} \mathrm{Pu}$ & \\
\hline
\end{tabular}

\subsubsection{Requirements for Confirmation of Conservatism}

For preclosure criticality analyses, two aspects of the isotopic model (BSC 2004d) for CSNF must be addressed. First, values for the initial isotopic concentrations must be conservative with respect to their contribution towards criticality. Second, changes to the initial isotopic concentration values as a function of time must also be conservative with respect to their contribution towards criticality. Proposed requirements addressing these aspects are presented in this section. Confirmation of the conservatism in the isotopic model used for burnup credit for CSNF will be demonstrated in analyses that will support licensing activities.

- Reactor operating histories and conditions must be selected together with axial burnup profiles such that the isotopic concentrations used to represent CSNF assemblies in preclosure criticality analyses shall produce values for $\mathrm{k}_{\text {eff }}$ that are conservative in comparison to any other expected combination of reactor history, conditions, or profiles. This will ensure initial isotopic concentrations (i.e., at time of discharge from the reactor) are conservative with respect to criticality. Alternatively, additional margin may be added to account for uncertainties, including axial effects, in isotopic concentrations. 
- Values for the isotopic concentrations representing CSNF must produce conservative values for $\mathrm{k}_{\mathrm{eff}}$ for all preclosure time periods for which criticality analyses are performed. This ensures changes to the initial isotopic concentration values as a function of time will also be conservative with respect to criticality.

The first requirement addresses axial burnup effects. The quantities and distributions of the isotopics are governed by the local neutron spectrum, which depends upon the reactor operating history. Local neutron spectra effects are modeled for the burnup calculations by including local power density, moderator density, and fuel temperatures, as well as soluble boron concentrations for the burnup period of interest. However, for preclosure criticality analyses, detailed modeling of reactor operating histories and conditions is not practical. Therefore, bounding values will be chosen for parameters representing reactor operating histories and conditions. As for postclosure analysis (YMP 2003, Section 3.5.2.1.3), axial profile effects will be accounted for by using either conservative isotopic concentrations, or conservative profiles, or both. Analyses will be performed using the isotopic model (BSC 2004d), and the sufficiency of the fuel assembly database used in satisfying the first requirement will be demonstrated. Alternatively, additional margin may be added to account for uncertainties, including axial effects, in isotopic concentrations.

The second requirement addresses changes to the initial isotopic concentration values, as a function of time, for preclosure. Uncertainties in $\mathrm{k}_{\mathrm{eff}}$ resulting from uncertainties in the half-life and branching fractions can be established as a function of enrichment, burnup, and decay time. Satisfying the second requirement will necessitate repeatedly applying the method for treating uncertainties in isotopic decay to a range of sets of initial isotopic concentrations to determine the largest values for uncertainty in $\mathrm{k}_{\mathrm{eff}}$.

These requirements are provided to ensure assumptions used in modeling fuel depletion (and decay) are conservative with respect to criticality.

\subsection{EFFECTIVE NEUTRON MULTIPLICATION FACTOR $\left(\mathrm{k}_{\mathrm{eff}}\right)$ CALCULATION}

The Criticality Model (BSC 2004c) will be used for evaluating the criticality potential of | configurations of fissionable materials at Yucca Mountain. The criticality evaluations for preclosure will be performed using the Monte Carlo simulation method (implemented by MCNP) for solving the neutron transport equation (BSC 2004c, Section 6.1). MCNP is a general purpose Monte Carlo N-Particle code that can be used for neutron, photon, electron, or coupled neutronphoton-electron transport including the capability to calculate eigenvalues for various systems. The code treats an arbitrary three-dimensional configuration of materials in geometric cells bounded by first- and second-degree surfaces and fourth-degree elliptical tori (Briesmeister 1997, p. ix).

The Monte Carlo method is based on following a number of individual neutrons through their transport, including interactions such as scattering, fission and absorption, and leakage. The probability distributions governing these events are statistically sampled to describe the total phenomenon. The cross-sections for the various neutron interactions dictate the reaction required for the criticality calculation at each interaction site. The fission process is regarded as the birth event that separates generations of neutrons. A generation is the lifetime of a neutron 
from birth by fission, to loss by escape, parasitic capture, or absorption leading to fission. The average behavior of a sample set of neutrons is used to estimate the average behavior of the system with regard to the number of neutrons in successive generations (i.e., $\mathrm{k}_{\mathrm{eff}}$ ).

The Monte Carlo method allows explicit geometrical modeling of material configurations. Using appropriate material cross-section data in the criticality calculation is essential to obtaining credible results. The accuracy of the Monte Carlo method for criticality calculations is limited only by the accuracy of the material cross-section data, a correct explicit modeling of the geometry, and the duration of the computation. The accuracy of the method and cross-section data is established by evaluating critical experiments. Nuclear cross-section data are available from several source evaluations (data libraries). The choice of specific cross-section data will be evaluated during criticality model validation and documented in the analyses that will support licensing activities.

\subsection{VALIDATION}

Validation is the process of determining the applicability of a computational method and establishing the bias of the method by using benchmarks appropriate for the intended evaluation of operations. This section presents a description of this process for calculating the criticality potential of a waste form.

During the process of validation, criticality experiments are selected from three types of experimental data-laboratory critical experiments, $\mathrm{CRCs}$, and radiochemical assays. It should be noted that out-of-package operations model validation will use only laboratory critical experiments, and not the isotopic model.

Laboratory critical experiments are used to benchmark the Criticality Model (BSC 2004c) (as part of the validation) for a range of fissionable materials, enrichments of fissile isotopes, moderator materials, absorber materials, and configurations. CRCs are used to benchmark the Criticality Model (BSC 2004c) for intact initial configurations of CSNF.

\subsubsection{Upper Subcritical Limit Determination}

An essential element of the Criticality Model (BSC 2004c) used for calculating $k_{\text {eff }}$ for a waste form configuration is the determination of the critical limit (CL). The CL is derived from the bias and uncertainties associated with the criticality code and modeling process. The CL for a waste form configuration is a limiting value of $\mathrm{k}_{\text {eff }}$ at which a configuration is considered potentially critical. An upper subcritical limit (USL) is an upper limit placed on $\mathrm{k}_{\text {eff }}$ to ensure subcriticality with allowances made for the bias and uncertainty in the calculation model as well as an administrative criticality safety margin. The administrative criticality safety margin is the difference between a CL and a USL, illustrated as follows:

$$
\begin{gathered}
\mathrm{CL}=1-\text { sum of bias and uncertainties } \\
\mathrm{USL}=\mathrm{CL}-\text { administrative margin }
\end{gathered}
$$

The CL is characterized by statistical tolerance limits that account for biases and uncertainties associated with the criticality code trending process, and any uncertainties due to extrapolation 
outside the range of experimental data, or limitations in the geometrical or material representations used in the computational method.

A CL is associated with a specific type of waste form configuration. The CL is characterized by a representative set of benchmark criticality experiments. This set of criticality experiments also prescribes the basic range of applicability of the results.

To establish a CL requires: (1) selection of benchmark experiments; (2) establishment of the range of applicability of the benchmark experiments (identification of physical and spectral parameters that characterize the benchmark experiments); (3) establishment of a lower-bound tolerance limit; and, if necessary, (4) establishment of the penalties for extending the range of applicability.

\subsubsection{Selection of Critical Experiments}

Applications must discuss and justify the critical experiments (LCEs and CRCs) used in the validation, which includes establishment of the USL. For commercial fuel, these experiments will be chosen from a database that simulates low-enriched, light water, reactor-fuel arrays in configurations similar to those used in storage, handling, and waste package configurations. This will include both $\mathrm{UO}_{2}$ and mixed-oxide fuel compositions. The experiments for CSNF should contain uranium-enrichments from about 2.0 to $5.0 \mathrm{wt} \%{ }^{235} \mathrm{U}$ and plutonium-enrichments from 2 to $6 \mathrm{wt} \%{ }^{239} \mathrm{Pu}$. For defense high-level radioactive waste glass or DOE SNF, experiments that simulate their criticality characteristics will be chosen. If the database used does not cover the total range of parameters for the storage, handling, or waste package configurations, then those methods required for extending the range of applicability provided in Section 3.4.1.4 will be used.

\subsubsection{Range of Applicability}

The following discussion is taken from Disposal Criticality Analysis Methodology Topical Report (YMP 2003, Section 3.5.3.2.2) and also applies to preclosure criticality safety.

In ANSI/ANS-8.1-1983 (p. 1), the term "area of applicability" means "the limiting ranges of material compositions, geometric arrangements, neutron energy spectra and other relevant parameters (such as heterogeneity, leakage, interaction, absorption, etc.) within which the bias of a calculational method is established." The term "area of applicability" and range of applicability are used interchangeably here.

Bias is a measure of the systematic differences between the results of a calculational method and experimental data. Uncertainty is a measure of the random error associated with the difference between the calculated and measured result. When evaluating biases and uncertainties and choosing parameters (or areas) for which a bias would exhibit a trend, there are three fundamental areas (Lichtenwalter et al. 1997, p. 179) that should be considered:

1. Materials of the waste package and the waste form, especially the fissionable materials

2. The geometry of the waste package and waste forms

3. The inherent neutron energy spectrum affecting the fissionable materials. 
There are substantial variations within each of these categories that require further considerations. These are discussed in Lichtenwalter et al. (1997, p. 180). Quantifying the various categories of parameters is complicated and generally requires approaches that use benchmark experiments that are characterized by a limited set of physical and computed neutron parameters that are then compared with the neutronic parameters of a waste package.

In the general practice of characterizing biases and trends in biases, one would first look at those fundamental parameters that might create a bias. That is, what are the main parameters that could be in error and have the most significant effect on the accuracy of the calculation? Important areas for evaluating criticality are the geometry of the configuration, the concentration of important materials (reflecting materials, moderating materials, fissionable materials, and significant neutron absorbing materials), and the nuclear cross sections that characterize the nuclear reaction rates that will occur in a system containing fissionable and absorbing materials. Quite often, it is not simple to characterize the trends in a bias for some of the fundamental parameters chosen. In most cases, other parameters, called proxy parameters, will exhibit statistically definable trends. Generally, these proxy parameters reflect the effects of a combination of fundamental parameters; therefore, a proxy parameter is one that acts in the place of one or more fundamental parameters.

It is desirable that the range of the fundamental parameters of the benchmark critical experiments (range of applicability) and the range of the fundamental parameters of the system (range of parameters) evaluated be identical. This is not practical usually, and for those parameters that do not show a bias, it is acceptable to use critical benchmark experiments that cover most, but not all, of the range of parameters of the system under evaluation. In these situations, expert judgment may be used to determine if there is a reasonable assurance that the two are sufficiently close.

\subsubsection{Development of Lower-Bound Tolerance Limit Function}

The application of statistical methods to biases and uncertainties of $k_{\text {eff }}$ values is determined by trending criticality code results for a set of benchmark critical experiments that will be the basis of establishing lower-bound tolerance limits for a waste form. This process involves obtaining data on various neutronic parameters that are associated with the set of critical experiments used to model the code-calculated values for $k_{\text {eff. }}$ These data, with the calculated values of $k_{\text {eff }}$, are the basis of the calculation of the lower-bound tolerance limit function.

Since the determination of lower-bound tolerance limit functions for a waste form is data dependent, the set of benchmark critical experiments must be carefully selected to cover the range of parameters expected in the repository. Data quantity, diversity, and quality are important considerations to ensure appropriate range of applicability coverage for a waste form.

The lower-bound tolerance limit function for a waste form results from the process shown in Figure 2. The data set and the resulting $\mathrm{k}_{\text {eff }}$ values produced by the criticality code must be confirmed as appropriate and valid for the waste form. This is fundamental to the development of the lower-bound tolerance limit function. The objective of this process is to produce lower-bound tolerance limits that are statistically meaningful and practical in application. 
The purpose of the lower-bound tolerance limit function is to translate the benchmarked $\mathrm{k}_{\text {eff }}$ values from the criticality code to a design parameter for a waste form-waste package combination. This design parameter is used in criteria for determining criticality potential. To meet this purpose, it is necessary to account for criticality code calculation differences from the true value of the effective neutron multiplication factor of 1.0. This latter value is an assumption, as explained above. The lower-bound tolerance limit definition addresses biases and uncertainties that cause the calculation results to deviate from the true value of $\mathrm{k}_{\text {eff }}$ for a critical experiment, as reflected over an appropriate set of critical experiments.

Figure 2 displays two general statistical methods for establishing lower-bound tolerance limit functions: (1) regression-based methods reflecting criticality code results over a set of critical experiments that can be trended, and (2) random sample based methods that apply when trending is not an appropriate explanation of criticality code calculations. The regression approach addresses the calculated values of $\mathrm{k}_{\text {eff }}$ as a trend of spectral or physical parameters or both. That is, regression methods are applied to the set of $k_{\text {eff }}$ values to identify trending with such parameters. The trends show the results of systematic errors or bias inherent in the calculational method used to estimate criticality. In some cases, a data set may be valid, but might not cover the full range of parameters used to characterize the waste form. The area (or areas) of applicability of a calculational method may be extended beyond the range of the experimental conditions of the data set over which the bias is established by making use of correlated trends in the bias (see Section 3.4.1.4).

If no trend is identified, a single value may be established for a lower-bound tolerance limit that provides the desired statistical properties associated with the definition of this quantity. The data are treated as a random sample of data (criticality code values of $k_{\text {eff }}$ ) from the waste form population of interest and straightforward statistical techniques are applied to develop the lower-bound tolerance limit. For purposes of differentiation, this technique will be described as "nontrending." The normal-distribution tolerance limit method and the distribution-free tolerance limit method, described below, are "nontrending" methods. 


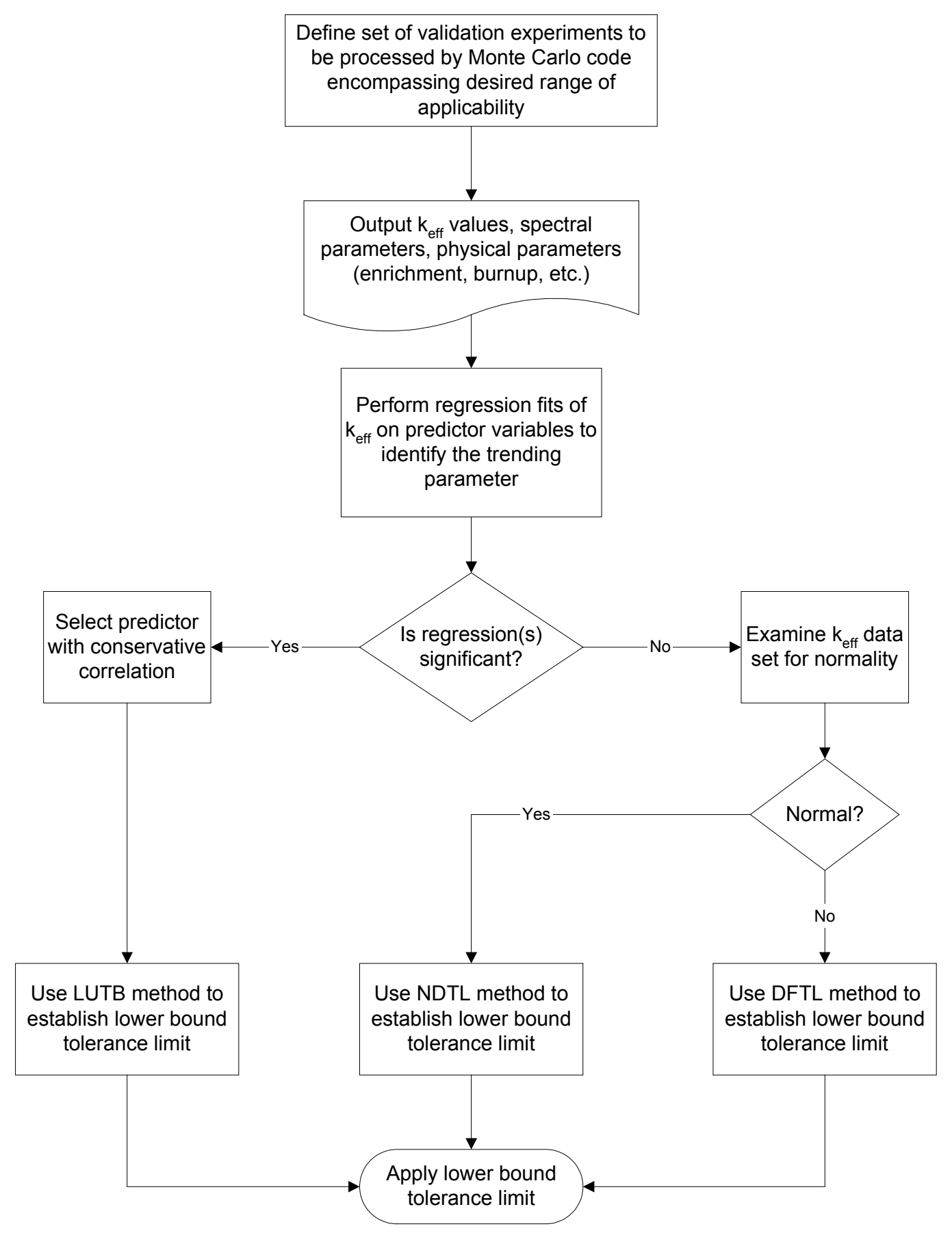

Note: LUTB Lower Uniform Tolerance Band

NDTL Normal Distribution Tolerance Limit

DFTL Distribution Free Tolerance Limit

Figure 2. Process for Calculating Lower-Bound Tolerance Limits

The regression or "trending" methods (YMP 2003, Section 3.5.3.2.7) use statistical tolerance values based on linear regression techniques to establish a lower-bound tolerance limit function. Trending in this context is linear regression of $k_{\text {eff }}$ on the predictor variable(s). Statistical significance of trending is determined by the test of the hypothesis in which the regression model mean square error is zero. Here the predictor variable(s) may be a parameter such as burnup, or 
a parameter that indicates the distribution of neutrons within the system, such as the average energy of a neutron that causes either fission or absorption. Where multiple candidates are found for trending purposes, each regression model will be applied and the conservative model will be used to determine the value of the lower-bound tolerance limit. The lower uniform tolerance band method, described below, trends a single parameter against $\mathrm{k}_{\text {eff. }}$. Multiple regression methods that trend multiple parameters against $\mathrm{k}_{\text {eff }}$ may also be used to establish the lower-bound tolerance limit function. In either single or multiple situations, the regression trend that produces the lowest lower-bound tolerance limit is defined to be the more conservative regression.

In nontrending situations, standard statistical tolerance limit methods, which characterize a proportion of a population with a confidence coefficient, are used to establish the single-valued lower-bound tolerance limit function that applies for the range of applicability of the set of critical experiments. There are two standard tolerance limit methods described, each specific to the result of examination of the hypothesis of normality of $k_{\text {eff }}$ values of the benchmark set of critical experiments. Disposal Criticality Analysis Methodology Report (YMP 2003, Section 3.5.3.2.8) addresses situations in which the distribution of the $\mathrm{k}_{\text {eff }}$ values for the set of benchmark critical experiments can be treated as coming from a normal probability distribution. This technique is the normal distribution tolerance limit. Section 3.5.3.2.9 of Disposal Criticality Analysis Methodology Report (YMP 2003) describes the distribution free tolerance limit method. The distribution free tolerance limit method applies when trending is not appropriate and data for benchmark critical experiments do not pass the test for normality. In this situation, there is no assumption about the form of the underlying probability model. Assumptions about the randomness of the process and the data as representing a random sample from the population of interest, however, are necessary.

In all calculations of lower-bound tolerance limit functions, the concept described as the "no positive bias" (Lichtenwalter et al. 1997, p. 160) rule must be accommodated. This rule excludes benefits for raising the lower-bound tolerance limit for cases in which the best estimate of the bias trend would result in a lower-bound tolerance limit greater than 1.0. The treatment of this element is discussed below in the context of each method used to establish the basic lower-bound tolerance limit function.

The lower-bound tolerance limit function is defined as:

$$
f(x)=k_{C}(x)-\Delta k_{C}(x)
$$

where

$$
\begin{aligned}
& \mathrm{x}=\text { parameter vector used for trending } \\
& \mathrm{k}_{\mathrm{C}}(\mathrm{x})=\text { the value obtained from a regression of the calculated } \mathrm{k}_{\text {eff }} \text { of benchmark } \\
& \text { critical experiments or the mean value of } \mathrm{k}_{\text {eff }} \text { for the data set if there is no } \\
& \text { trend } \\
& \Delta \mathrm{k}_{\mathrm{C}}(\mathrm{x})=\text { the uncertainty of } \mathrm{k}_{\mathrm{C}} \text { based on the statistical scatter of the } \mathrm{k}_{\text {eff }} \text { values of the } \\
& \text { benchmark critical experiments, accounting for the confidence limit, the } \\
& \text { proportion of the population covered, and the size of the data set. }
\end{aligned}
$$

The statistical description of the scatter quantifies the variation of the data set about the expected value and the contribution of the variability of the calculation of the $k_{\text {eff }}$ values for the benchmark critical experiments. 
Based on a given set of critical experiments, the lower-bound tolerance limit is estimated as a function ( $\mathrm{f}[\mathrm{x}])$ of a parameter(s). Because $\Delta \mathrm{k}_{\mathrm{C}}(\mathrm{x})$ and $\mathrm{k}_{\mathrm{C}}(\mathrm{x})$ can vary with this parameter, the lower-bound tolerance limit function is typically expressed as a function of this parameter vector, within an appropriate range of applicability derived from the parameter bounds, and other characteristics that define the set of critical experiments.

The calculational bias, $\beta$, is defined as:

$$
\beta=\mathrm{k}_{\mathrm{C}}-1
$$

and thus the uncertainty in the bias is identical to the uncertainty in $\mathrm{k}_{\mathrm{C}}$ (i.e., $\Delta \mathrm{k}_{\mathrm{C}}=\Delta \beta$ ). This makes the bias negative if $\mathrm{k}_{\mathrm{C}}$ is less than 1 and positive if $\mathrm{k}_{\mathrm{C}}$ is greater than 1.

To prevent taking credit for a positive bias, the lower-bound tolerance limit is further reduced by a positive bias adjustment. The positive bias adjustment sets $\mathrm{k}_{\mathrm{C}}$ equal to 1.0 when $\mathrm{k}_{\mathrm{C}}$ exceeds 1.0 .

Various sections of Disposal Criticality Analysis Methodology Report (YMP 2003) discuss the various methods for estimating a lower-bound tolerance limit function. Section 3.5.3.2.7 of the report presents the regression method for trending $\mathrm{k}_{\text {eff }}$ versus a parameter vector and Sections 3.5.3.2.8 and 3.5.3.2.9 detail the other two methods to be used if statistically significant trends cannot be identified via regression methods for a set of benchmark experiments.

An MCNP bias will be evaluated and determined for out-of-package and in-package operations using a selected set of critical experiments from the laboratory critical experiment database as well as CRCs from the CRC database. Of particular interest will be trends versus neutron spectral parameters and any of the control parameters that will be used for criticality control. A brief description of the critical experiments used for the determination of any biases and a validation of the trend or trends discovered will also be provided. Out-of-package operations will only use fresh fuel critical experiments for determining bias values.

\subsubsection{Extension of the Range of Applicability}

Where data are not available, it is prudent to use appropriate bounding models or assign additional penalties. In these cases, there may be an extension of the range of applicability to cover the range of parameters of the system.

The means used to extend the range of applicability will depend on a number of factors. These include, but are not necessarily limited to: (1) the nature of the critical experiments used to determine the range of applicability and trends with biases, (2) the particular waste form involved, and (3) the availability of other proven computer codes or methods used to evaluate the situation.

ANSI/ANS-8.1-1983 (p. 18) Appendix C, Section C4 will be used for the extension of the range of applicability:

The area (or areas) of applicability of a calculational method may be extended beyond the range of experimental conditions over which the bias is established by 
making use of correlated trends in the bias. Where the extension is large, the method should be:

A. Subjected to a study of the bias and potentially compensating biases associated with individual changes in materials, geometries or neutron spectra. This will allow changes, which can affect the extension to be independently validated. In practice, this can be accomplished in a stepwise approach; that is, benchmarking for the validation should be chosen (where possible) such that the selected experiments differ from previous experiments by the addition of one new parameter so the effect of only the new parameter, on the bias can be observed.

B. Supplemented by alternative calculational methods to provide an independent estimate of the bias (or biases) in the extended area (or areas) of applicability.

If a range of applicability is extended, where there is a trend in the data, without the use of additional experiments, additional penalty will be added to the criteria used to determine if a system has potential for criticality. The same techniques described above for extending the range of applicability when there are trends may be used to determine the additional penalty: (1) expert judgment (an evaluation by someone skilled, by training and experience, in criticality analysis), (2) sensitivity analysis, (3) statistical evaluation of the importance of these parameters, or (4) comparison with other credible methods (code-to-code comparisons).

For situations where a bias (trend) is not established, there are two options for extending the range of applicability. If the extension of the range of applicability is small and the performance of the criticality code for these parameter ranges is also understood, it would be appropriate to use the established lower bound tolerance limit and an appropriate penalty to calculate the critical limit. If the extension is not small, then more data, covering the range of applicability, will be necessary. When more data are obtained, the process illustrated in Figure 1 must be applied to the new data set. This applies when the range of applicability for fundamental parameters (material concentrations, geometry, or nuclear cross-sections) does not cover the range of parameters of the waste package configuration and no trend is exhibited.

\subsubsection{Upper Subcritical Limit Application}

Geometric modeling and inputs for computing the $\mathrm{k}_{\mathrm{eff}}$ for a critical experiment with a criticality code often induce bias in the resulting $\mathrm{k}_{\text {eff }}$ value. Bias is a measure of the systematic differences between the results of a calculational method and experimental data. Uncertainty is a measure of the random error associated with the difference between the calculated and measured result. These $k_{\text {eff }}$ values deviate from the expected result ( $k_{\text {eff }}$ equal to 1 ) of benchmark sets of critical experiments. The experimental value of $\mathrm{k}_{\mathrm{eff}}$ for some benchmarks may not be unity (some are extrapolations to critical); however, this value is used for purposes of calculating errors. 
The critical limit (CL) is represented in equation form as (based on ANSI/ANS-8.17-1984, Section 5):

$$
\mathrm{CL}(\mathrm{x})=\mathrm{f}(\mathrm{x})-\Delta \mathrm{k}_{\text {EROA }}-\Delta \mathrm{k}_{\text {ISO }}-\Delta \mathrm{k}_{\mathrm{m}}
$$

where

$\mathrm{x}=$ a neutronic parameter used for trending

$\mathrm{f}(\mathrm{x}) \quad=$ the lower-bound tolerance limit function accounting for biases and uncertainties that cause the calculation results to deviate from the true value of $\mathrm{k}_{\text {eff }}$ for a critical experiment, as reflected over an appropriate set of critical experiments

$\Delta \mathrm{k}_{\mathrm{EROA}}=$ penalty for extending the range of applicability

$\Delta \mathrm{k}_{\mathrm{ISO}}=$ penalty for isotopic composition bias and uncertainty

$\Delta \mathrm{k}_{\mathrm{m}}=$ an arbitrary margin ensuring subcriticality for preclosure analyses, turning the CL function into an USL function

Based on a given set of critical experiments, the USL is estimated as a function of a trending parameter for the experiments. Because $\mathrm{CL}(\mathrm{x})$ can vary with this parameter, the USL is expressed as a function of this parameter within an appropriate range of applicability derived from the parameter bounds.

For the preclosure period, USLs will be determined as prediction limits, at the user-specified confidence level, using the techniques described in Disposal Criticality Analysis Methodology Topical Report (YMP 2003, Section 3.5.3.2).

Part of the range of applicability of a benchmark data set is based on the range of parameter variation in the benchmark experiments that are used for estimating the USL. The other part is based on the range of fundamental parameters of the benchmark experiments. Lichtenwalter et al. (1997, p. 163) define three classes of fundamental characteristics from which a fundamental parameter may be defined. The three characteristics are (1) materials of construction (including fissionable materials), (2) the geometry of construction, and (3) the inherent neutron energy spectrum affecting the fissionable material(s).

Once fundamental parameters and a set of critical experiments have been established, calculated values of $k_{\text {eff }}$ are trended against a number of these parameters to determine the parameter that provides the best fit to the data from the benchmark critical experiments. This parameter may be used for extending the range of applicability to the waste form.

The repository will contain various types of waste forms, the majority of which will be CSNF, comprised of two waste forms: PWR and BWR SNF. Each waste form will be analyzed separately for criticality potential and characterized with a set of benchmark critical experiments that span the characteristics of the particular waste form. This includes analyzing potential critical configurations during the receiving, packaging, and emplacing operations. Analyses for each of these operations may require different sets of benchmark critical experiments since the neutronic parameters may change between operations. For example, the geometric structure of potential critical configurations will be different during the receiving operation (i.e., during 
handling of the waste form) than during the emplacing operation (intact waste package); therefore, this difference must be accommodated in the benchmark data set.

For CSNF in-package operations, CRC data are being used as benchmark data to estimate USLs for a limited range. For all CSNF out-of-package operations, including damaged fuel operations, a fresh fuel assumption will be used which restricts the benchmark data set for determining subcritical limits to fresh fuel laboratory critical experiments.

\subsection{UPPER SUBCRITICAL LIMIT CRITERION}

For preclosure, a USL criterion is used for comparison to predicted $\mathrm{k}_{\text {eff }}$ values to determine a configuration's criticality potential. The USL is an upper limit placed on $\mathrm{k}_{\mathrm{eff}}$ to ensure subcriticality, with allowances made for the bias and uncertainty in the calculation model, as well as an administrative criticality safety margin. A predicted $\mathrm{k}_{\mathrm{eff}}$ greater than or equal to the USL indicates a configuration in violation of the administrative safety limit. A predicted $k_{\text {eff }}$ less than the USL indicates that the configuration has no criticality potential.

A USL is estimated such that a calculated $\mathrm{k}_{\mathrm{eff}}$ on or below this limit is subcritical, and a system is considered acceptably subcritical if a calculated $\mathrm{k}_{\text {eff }}$ plus calculation uncertainties and margin lies at, or below, this limit. In equation notation, the USL criterion is defined as:

$$
\mathrm{k}_{\mathrm{S}}+\Delta \mathrm{k}_{\mathrm{S}} \leq \mathrm{USL}
$$

where

$$
\begin{aligned}
\mathrm{k}_{\mathrm{S}}= & \text { calculated } \mathrm{k}_{\mathrm{eff}} \text { for the system } \\
\Delta \mathrm{k}_{\mathrm{S}}= & \text { an allowance for: } \\
& \text { (a) statistical or convergence uncertainties, or both in the computation of } \mathrm{k}_{\mathrm{s}} \\
& \text { (b) material and fabrication tolerances, and } \\
& \text { (c) uncertainties due to the geometric or material representations used in the } \\
& \text { computational method [Note: allowance for items (b) and (c) can be obviated } \\
& \text { by using bounding representations] } \\
\mathrm{USL}= & \text { the value characterized by statistical tolerance limits that account for biases and } \\
& \text { uncertainties associated with the criticality code trending process, any } \\
& \text { uncertainties due to extrapolation outside the range of experimental data, or } \\
& \text { limitations in the geometrical or material representations used in the } \\
& \text { computational method, and an administrative margin-to-criticality that can } \\
& \text { reduce the CL(x) (current practices suggest a value of } 0.05 \text { [Kopp 1998, p. 4]) }
\end{aligned}
$$

\subsection{APPLICATION}

A description of the base input parameters for all of the criticality analyses including a general design arrangement of the areas to be evaluated will be provided in each analysis. Also, the evaluation of reactivity effects due to manufacturing tolerance for the waste package and components as well as uncertainties related to storage of a waste package prior to loading will be provided. Other structural and thermal-hydraulic effects will also be addressed. 
Each configuration used in these analyses will provide a calculated $\mathrm{k}_{\mathrm{eff}}$ based upon nominal dimensions. Adjustments will be made to the calculated $\mathrm{k}_{\mathrm{eff}}$ to contain the maximum $\mathrm{k}_{\mathrm{eff}}\left(\mathrm{k}_{\max }\right)$. The maximum multiplication factor $\mathrm{k}_{\max }$ will be a sum of the calculated $\mathrm{k}_{\mathrm{eff}}$ from the criticality software (e.g., MCNP) calculation plus biases and uncertainties that result from a number of other conditions, e.g., the manufacturing tolerances, structural and thermal-hydraulic effects mentioned earlier.

Any computer codes used to provide code-to-code verification will be described, critical experiments used to provide the verification will be discussed, and the results documented.

\subsubsection{Loading Restrictions for Commercial Spent Nuclear Fuel}

A single-parameter regression analysis will be performed, using the initial enrichment and burnup, for all potential CSNF assemblies in the repository to determine loading restrictions, or curves, for in-package operations. In these analyses, calculations will be made to determine acceptable enrichment and burnup pairs that can be loaded into a waste package. There may be different waste packages for different classes of enrichment-burnup pairs. Acceptable pairs are those combinations that yield a $\mathrm{k}_{\text {eff }}$ less than the USL. Design and statistical uncertainty will be added to the $\mathrm{k}_{\mathrm{eff}}$ calculated before comparing to the USL.

Having established a series of acceptable values for $\mathrm{k}_{\mathrm{eff}}$ for these configurations, a regression analysis will be performed. The burnup, in terms of either $\mathrm{MWd} / \mathrm{MTU}$ or $\mathrm{GWd} / \mathrm{MTU}$, will be formulated as a function of the nominal enrichment. Uncertainty in burnup values will also be incorporated into these regressions. A more detailed explanation of a process to determine loading curve restrictions is given below in this section. An example of a loading curve is presented in Appendix A.

A loading curve is prepared for loading fuel assemblies in the waste package in a manner similar to that used for spent nuclear fuel pools that are approved for burnup credit. The process for developing the loading curves for CSNF involves the following steps:

1. CSNF isotopic concentration data is generated for a range of enrichment and burnup pairs using the isotopic model (BSC 2004d).

2. Waste package configurations to evaluate for preclosure and postclosure are determined.

3. Administrative limits for the configurations, the upper subcritical limit for the preclosure configuration, and the critical limit for the postclosure configurations are determined, as described in the Criticality Model (BSC 2004c). These limits include the bias and uncertainties. The difference between the administrative limits is that the upper subcritical limit includes an administrative margin (i.e., 5 percent).

4. For each initial enrichment, burnup is varied, and the $\mathrm{k}_{\mathrm{eff}}$ and corresponding $\sigma$ (uncertainty) of the configuration with the different burnups is calculated.

5. A curve of $k_{\text {eff }}$ plus $2 \sigma$ (collectively referred to as $k_{\text {eff }}$ ) versus burnup is generated from the results for each configuration and initial enrichment. Figure A-1 in Appendix A 
shows an example of a calculated required minimum burnup used to generate a loading curve. Those data points where $k_{\text {eff }}$ exceeds the administrative limit (above the line) do not have enough burnup to be critically safe. Data points on or below the administrative limit are acceptable. The intersection of the calculated $k_{\text {eff }}$-versusburnup curve and the administrative limit line defines the required minimum burnup for the selected initial enrichment value (See Figure A-1 in Appendix A).

6. The burnup values at the intersection of the calculated $k_{\text {eff-versus-burnup curve for the }}$ different initial enrichments are plotted against the initial enrichment values on a single curve to generate the loading curve for each particular waste package (e.g., Figure A-2 in Appendix A).

7. The burnup values are then adjusted to account for the uncertainty in the reported burnup values. The adjustment is a percentage in burnup that gives a 95/95 confidence and probability level.

8. A polynomial equation is then fit to the adjusted burnup values and plotted on an initial enrichment-versus-burnup curve to generate the criticality loading curve for the specific waste package configuration and range of fuel types covered. The area above the curve includes the acceptable SNF because the burnup in this area exceeds the required minimum burnup. The area below the curve defines unacceptable SNF, which cannot be loaded into the particular waste package (see Figure A-2 in Appendix A). All CSNF assemblies can be accommodated in some waste package using some combination of additional criticality control and/or loading schemes.

\subsubsection{Out-of-Package Criticality Safety}

Criticality safety calculations for out-of-package operations will focus on the following:

- Safe Design for Storage Racks-The design of storage racks will include the use of fixed burnable neutron absorbers (poisons), as required, to ensure subcriticality for Category-1 and Category- 2 event sequences. Wet and dry storage rack conditions will be considered as part of the evaluation and will include partial flooding as well as varying moderator density in order to include all credible conditions. The most reactive fuel assemblies and canister conditions will be used in the calculations along with the processes described in Section 2.2.7.

- Safe Design in Handling-Event sequences involving mishandling SNF will be evaluated including placement outside of storage racks, misplacement inside storage racks, and dropping of SNF when it is handled. Additionally, the possible reconfiguration of SNF will be considered as a result of dropping.

- Fixed Neutron Absorber Burnup-Evaluation of fixed neutron absorbers for storage rack design is required to ensure sufficient neutron absorbers will remain over the life of the facility. Limited fixed neutron absorber credit of 75 percent will be used in the design of fixed neutron absorbers as specified in NUREG-1567 (NRC 2000, Section 8.4.1.1), unless comprehensive fabrication acceptance tests capable of verifying the 
presence and uniformity of the neutron absorber are implemented. To ensure subcriticality over the life of the facility, the regulatory requirement of 10 CFR Part 72.124(b) “...Where solid neutron absorbing materials are used, the design must provide for positive means of verifying their continued efficacy..." will be implemented by using the maximum credible neutron flux for a given configuration in depletion calculations of fixed neutron absorbers.

Using the above criteria, the process for criticality design calculations for CSNF in the surface facility (BSC 2004b) can be summarized as follows. The most reactive PWR and BWR fuel assemblies will be identified by calculation of $k_{\text {eff }}$ for fully moderated single assemblies containing fresh fuel. For storage rack design, calculations will be performed to confirm that the same assembly designs remain the most reactive in the presence of fixed absorbers. Using the most reactive fuel assemblies, assembly spacing for storage rack design will be determined by computing $\mathrm{k}_{\mathrm{eff}}$ as a function of assembly pitch for different average (uniform) fuel enrichments, and comparing the computed values of $\mathrm{k}_{\text {eff }}$ to the USL determined by the process described in Section 3.4.1. Calculations of $k_{\text {eff }}$ will be performed for racks with and without fixed neutron absorber to evaluate absorber effectiveness. In addition, calculations will be performed for a range of uniform moderator densities covering the range from dry to fully moderated conditions, as well as for partial flooding, to ensure that optimum moderation has been considered.

The process for criticality safety analyses in the surface facility can be summarized as follows. Using Category 1 and Category 2 event sequences identified as part of the preclosure safety analysis, as described in Section 3.1, criticality safety analyses will be performed for the identified event sequences. The analyses for some kinds of event sequences (e.g., those related to transportation casks) may simply note that compliance with existing regulations (e.g., 10 CFR Parts 50,71, and 72) provides sufficient assurance of criticality safety. Where necessary (e.g., reconfiguration of fuel pins or relocation of assemblies due to drops or collisions), additional calculations of $\mathrm{k}_{\mathrm{eff}}$ will be performed to demonstrate that subcriticality is maintained. 


\section{CONCLUSIONS}

The process for analyzing the potential for criticality during the preclosure period will be dictated by existing regulatory requirements. The proposed process is based on the fact that planned preclosure operations and facilities have significant similarities to existing facilities and operations currently regulated by the NRC. The major difference is the use of a risk-informed approach with burnup credit for in-package operations.

The probability of success for this proposed licensing strategy is increased, since there exist both precedents of regulation (10 CFR Part 63; NRC 2002a, Section 5) and commercial precedents for allowing burnup credit at sites similar to Yucca Mountain during preclosure. While NUREG1520 (NRC 2002a, Section 5) is not directly applicable to a facility for handling spent nuclear fuel, the risk-informed approach to criticality analysis in NUREG-1520 (NRC 2002a, Section 5) provides insight into the NRC's approach to risk-informed criticality analysis.

The types of event sequences which must be considered during the criticality safety analysis are those events which result in unanticipated moderation, loss of neutron absorber, geometric changes in the critical system, or administrative errors in waste form placement (loading) of the waste package. The specific events to be considered must be based on the review of the system's design, as discussed in Section 3.1. 


\section{INTENTIONALLY LEFT BLANK}




\section{REFERENCES}

\subsection{DOCUMENTS CITED}

Briesmeister, J.F., ed. 1997. MCNP-A General Monte Carlo N-Particle Transport Code. LA12625-M, Version 4B. Los Alamos, New Mexico: Los Alamos National Laboratory. ACC: MOL.19980624.0328.

BSC (Bechtel SAIC Company) 2003a. Commercial Spent Nuclear Fuel Waste Package Misload Analysis. CAL-WHS-MD-000003 REV 00A. Las Vegas, Nevada: Bechtel SAIC Company. ACC: DOC.20031002.0005.

BSC 2003b. Preclosure Safety Analysis Guide. TDR-MGR-RL-000002 REV 01. Las Vegas, Nevada: Bechtel SAIC Company. ACC: DOC.20031028.0002.

BSC 2004a. Technical Work Plan for: Criticality Department Work Packages ACRM01 and NSN002. TWP-EBS-MD-000014 REV 02. Las Vegas, Nevada: Bechtel SAIC Company. ACC: DOC.20040408.0003.

BSC 2004b. Surface Facility Criticality Safety Calculations. 100-00C-WHS0-00100-000-00B. Las Vegas, Nevada: Bechtel SAIC Company. ACC: ENG.20040309.0001.

BSC 2004c. Criticality Model. CAL-DS0-NU-000003 REV 00A. Las Vegas, Nevada: Bechtel SAIC Company. ACC: DOC.20040913.0008.

BSC 2004d. Isotopic Model for Commercial SNF Burnup Credit. CAL-DSU-NU-000007 REV 00A. Las Vegas, Nevada: Bechtel SAIC Company. ACC: DOC.20040818.0001.

BSC 2004e. Categorization of Event Sequences for License Application. 000-00C-MGR0-00800000-00A. Las Vegas, Nevada: Bechtel SAIC Company. ACC: ENG.20040722.0001.

BSC 2004f. 21-PWR Waste Package with Absorber Plates Loading Curve Evaluation. CALDSU-NU-000006 REV 00B. Las Vegas, Nevada: Bechtel SAIC Company. ACC:

DOC.20040922.0004.

Canori, G.F. and Leitner, M.M. 2003. Project Requirements Document. TER-MGR-MD000001 REV 02. Las Vegas, Nevada: Bechtel SAIC Company. ACC: DOC.20031222.0006.

CRWMS M\&O 2000. Waste Packages and Source Terms for the Commercial 1999 Design Basis Waste Streams. CAL-MGR-MD-000001 REV 00. Las Vegas, Nevada: CRWMS M\&O. ACC: MOL.20000214.0479.

Curry, P.M. 2004. Project Functional and Operational Requirements. TDR-MGR-ME-000003 REV 02. Las Vegas, Nevada: Bechtel SAIC Company. ACC: DOC.20040714.0003. 
DOE (U.S. Department of Energy) 2004. Quality Assurance Requirements and Description. DOE/RW-0333P, Rev. 16. Washington, D.C.: U.S. Department of Energy, Office of Civilian Radioactive Waste Management. ACC: DOC.20040907.0002.

Kopp, L. 1998. "Guidance on the Regulatory Requirements for Criticality Analysis of Fuel Storage at Light-Water Reactor Power Plants." Memorandum from L. Kopp (NRC) to T. Collins (NRC), August 19, 1998, with attachment. ACC: HQO.19990520.0004.

Lichtenwalter, J.J.; Bowman, S.M.; DeHart, M.D.; and Hopper, C.M. 1997. Criticality Benchmark Guide for Light-Water-Reactor Fuel in Transportation and Storage Packages. NUREG/CR-6361. Washington, D.C.: U.S. Nuclear Regulatory Commission. TIC: 233099.

NEA (Nuclear Energy Agency) 2001. International Handbook of Evaluated Criticality Safety Benchmark Experiments. 2001 Edition. NEA/NSC/DOC(95)03. Paris, France: Nuclear Energy Agency, Organization for Economic Co-operation and Development. TIC: 251945.

NRC (U.S. Nuclear Regulatory Commission) 1997. Standard Review Plan for Dry Cask Storage Systems. NUREG-1536. Washington, D.C.: U.S. Nuclear Regulatory Commission.

ACC: MOL.20010724.0307.

NRC 1998. Rochester Gas and Electric Corporation, Docket No. 50-244, R.E. Ginna Nuclear Power Plant, Amendment to Facility Operating License. Amendment No. 72, License No.

DPR-18. Washington, D.C.: U.S. Nuclear Regulatory Commission. TIC: 245281.

NRC 2000. Standard Review Plan for Spent Fuel Dry Storage Facilities. NUREG-1567. Washington, D.C.: U.S. Nuclear Regulatory Commission. TIC: 247929.

NRC 2001. Interim Staff Guidance - 15. Materials Evaluation. ISG-15. Washington, D.C.: U.S. Nuclear Regulatory Commission. ACC: MOL.20030213.0154.

NRC 2002a. Standard Review Plan for the Review of a License Application for a Fuel Cycle Facility. NUREG-1520. Washington, D.C.: U.S. Nuclear Regulatory Commission. TIC: 253141.

NRC 2002b. Interim Staff Guidance - 8, Revision 2. Burnup Credit in the Criticality Safety Analyses of PWR Spent Fuel in Transport and Storage Casks. ISG-8, Rev 2.Washington, D.C.: U.S. Nuclear Regulatory Commission. ACC: MOL.20030124.0248.

NRC 2002c. "Interim Staff Guidance - 1. Damaged Fuel." ISG-1 Washington, D.C.: Nuclear Regulatory Commission. Accessed 06/28/2003. Readily Available. http://www.nrc.gov/reading-rm/doc-collections/isg/spent-fuel.html.

NRC 2002d. "Interim Staff Guidance - 11, Revision 2. Cladding Considerations for the Transportation and Storage of Spent Fuel." ISG-11, Rev. 2. Washington, D.C.: U.S. Nuclear Regulatory Commission. Accessed February 19, 2003. ACC: MOL.20030219.0134. http:/www.nrc.gov/reading-rm/doc-collections/isg/spent-fuel.html 
NRC 2003. Yucca Mountain Review Plan, Final Report. NUREG-1804, Rev. 2. Washington, D.C.: U.S. Nuclear Regulatory Commission, Office of Nuclear Material Safety and Safeguards. TIC: 254568.

Reamer, C.W. 2001. "U.S. Nuclear Regulatory Commission/U.S. Department of Energy Technical Exchange and Management Meeting on Pre-closure Safety (July 24-26, 2001)." Letter from C.W. Reamer (NRC) to S. Brocoum (DOE/YMSCO), August 14, 2001, with enclosure. ACC: MOL.20010925.0118.

Regulatory Guide 3.60, Rev. 0. 1987. Design of an Independent Spent Fuel Storage Installation (Dry Storage). Washington, D.C.: U.S. Nuclear Regulatory Commission. Readily available.

Regulatory Guide 3.71. 1998. Nuclear Criticality Safety Standards for Fuels and Material Facilities. Washington, D.C.: U.S. Nuclear Regulatory Commission. Readily available.

YMP (Yucca Mountain Site Characterization Project) 2003. Disposal Criticality Analysis Methodology Topical Report. YMP/TR-004Q, Rev. 02. Las Vegas, Nevada: Yucca Mountain Site Characterization Office. ACC: DOC.20031110.0005.

\subsection{CODES, STANDARDS, REGULATIONS, AND PROCEDURES}

10 CFR 50. 2002. Energy: Domestic Licensing of Production and Utilization Facilities. Readily available.

10 CFR 63. Energy: Disposal of High-Level Radioactive Wastes in a Geologic Repository at Yucca Mountain, Nevada. Readily available.

10 CFR 70. Energy: Domestic Licensing of Special Nuclear Material. Readily available.

10 CFR 71. Energy: Packaging and Transportation of Radioactive Material. Readily available.

10 CFR 72. Energy: Licensing Requirements for the Independent Storage of Spent Nuclear Fuel, High-Level Radioactive Waste, and Reactor-Related Greater than Class C Waste. Readily available.

ANSI/ANS-8.1-1983. Nuclear Criticality Safety in Operations with Fissionable Materials Outside Reactors. La Grange Park, Illinois: American Nuclear Society. TIC: 231616.

ANSI/ANS-8.3-1997. Criticality Accident Alarm System. La Grange Park, Illinois: American Nuclear Society. TIC: 240265.

ANSI/ANS-8.5-1996. Use of Borosilicate-Glass Raschig Rings as Neutron Absorber in Solutions of Fissile Material. La Grange Park, Illinois: American Nuclear Society. TIC: 252759.

ANSI/ANS-8.7-1998. 1999. American National Standard for Nuclear Criticality Safety in the Storage of Fissile Materials. La Grange Park, Illinois: American Nuclear Society. TIC: 253030. 
ANSI/ANS-8.10-1983. Criteria for Nuclear Criticality Safety Controls in Operations with Shielding and Confinement. La Grange Park, Illinois: American Nuclear Society.

TIC: 205015.

ANSI/ANS-8.12-1987. American National Standard for Nuclear Criticality Control and Safety of Plutonium-Uranium Fuel Mixtures Outside Reactors. La Grange Park, Illinois: American Nuclear Society. TIC: 205014.

ANSI/ANS-8.15-1981. Nuclear Criticality Control of Special Actinide Elements. La Grange Park, Illinois: American Nuclear Society. TIC: 231624.

ANSI/ANS-8.17-1984. Criticality Safety Criteria for the Handling, Storage, and Transportation of LWR Fuel Outside Reactors. La Grange Park, Illinois: American Nuclear Society. TIC: 231625.

ANSI/ANS-8.19-1996. American National Standard, Administrative Practices for Nuclear Criticality Safety. La Grange Park, Illinois: American Nuclear Society. TIC: 247691.

ANSI/ANS-8.21-1995. American National Standard for the Use of Fixed Neutron Absorbers in Nuclear Facilities Outside Reactors. La Grange Park, Illinois: American Nuclear Society. TIC: 247030.

ANSI/ANS-8.22-1997. American National Standard for Nuclear Criticality Safety Based on Limiting and Controlling Moderators. La Grange Park, Illinois: American Nuclear Society. TIC: 235109. 


\section{APPENDIX A - LOADING OF A WASTE PACKAGE}

\section{A. INTRODUCTION}

This appendix provides an example calculation of loading restrictions (loading curve), taken from 21-PWR Waste Package with Absorber Plates Loading Curve Evaluation (BSC 2004f).

\section{A.1 LOADING CURVES FOR A WASTE PACKAGE}

The purpose of this example loading curve calculation was to determine the required minimum burnup as a function of initial PWR assembly enrichment that permits loading of fuel into a 21-PWR waste package. The results are intended to provide an example of how PWR SNF assemblies whose actual burnup exceeds the required minimum burnup may be loaded into a 21-PWR waste package with a borated steel criticality control basket design.

An example of a determination of a minimum required burnup for a specific enrichment is shown in Figure A-1, which was adapted from Figure 13 of 21-PWR Waste Package with Absorber Plates Loading Curve Evaluation (BSC 2004f). In the example shown, the initial enrichment is $4.0 \mathrm{wt}^{\%}{ }^{235} \mathrm{U}$. The calculated $\mathrm{k}_{\text {eff }}$ values include a two- $\sigma$ allowance for computational uncertainty. The required minimum burnup for this example is $29.5 \mathrm{GWd} / \mathrm{MTU}$, determined from the intersection of the line representing the USL and the curve of the calculated $\mathrm{k}_{\text {eff }}$ values.

A loading curve using burnup credit depicts the relationship between the initial enrichment of a fuel assembly and the required minimum average burnup needed to suppress the reactivity of that fuel assembly sufficiently to allow it to be safely loaded into the waste package. Any assembly with burnup that exceeds the required minimum burnup, given the initial enrichment of the fuel assembly, may be placed in the waste package. The points for the loading curve are determined by taking the required minimum burnup from curves like that in Figure A-1 for a range of enrichments sufficient to cover the fuel inventory of interest.

The example loading curves in Figure A-2 show the required minimum burnup for fuel with initial ${ }^{235} \mathrm{U}$ enrichments from 2.0 to $5.0 \mathrm{wt} \%$, adapted from Figure 34 of 21-PWR Waste Package with Absorber Plates Loading Curve Evaluation (BSC 2004f). When these burnups are plotted against the enrichments, the resulting curve determines the loading restrictions for a waste package. The solid blue curve is the preclosure loading curve without consideration of burnup uncertainty. The solid red curve is a quintic polynomial that was fit to the preclosure loading curve including a 5-percent adjustment for burnup uncertainty. That is, the minimum burnup required for a given initial enrichment has been increased by 5 percent to account for uncertainty associated with assembly burnup records. The squares in the legend indicate number groupings of assemblies at a particular burnup and enrichment (e.g., 100-199 indicates that there are 100 to 199 assemblies at a listed burnup and enrichment) for a 10-year-old youngest fuel first arrival scenario for 63,000 MTU of CSNF, taken from Attachment III of Waste Packages and Source Terms for the Commercial 1999 Design Basis Waste Streams (CRWMS M\&O 2000). The area to the left of the curve in Figure A-2 shows acceptable enrichment-burnup pairs for SNF assemblies that can be loaded. The area to the right defines unacceptable assemblies for loading in the applicable waste package. These will need to be accommodated for by using some combination of additional criticality control and/or loading scheme. 


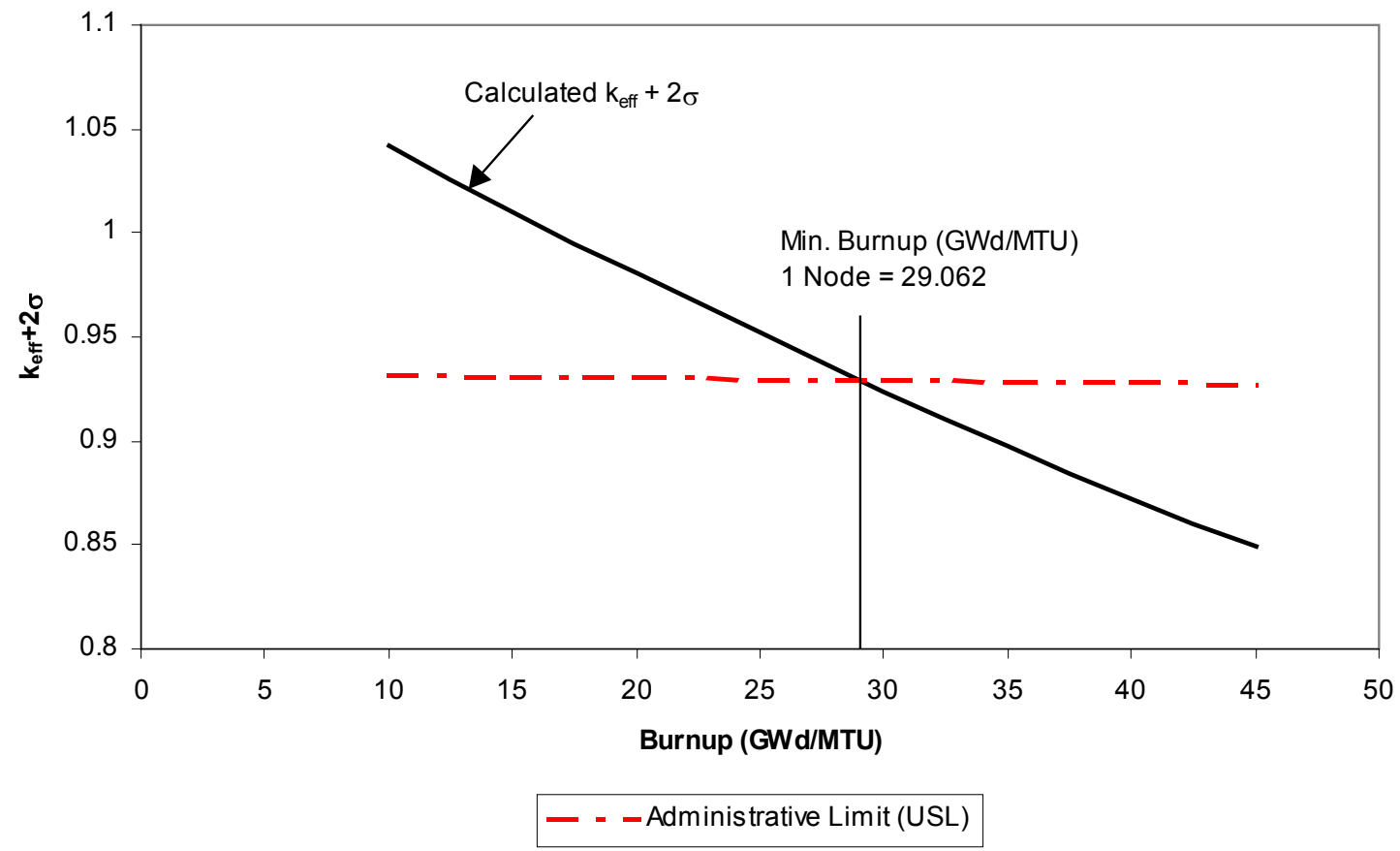

Figure A-1. Required Minimum Burnup for 4.0 wt\% Enriched PWR SNF

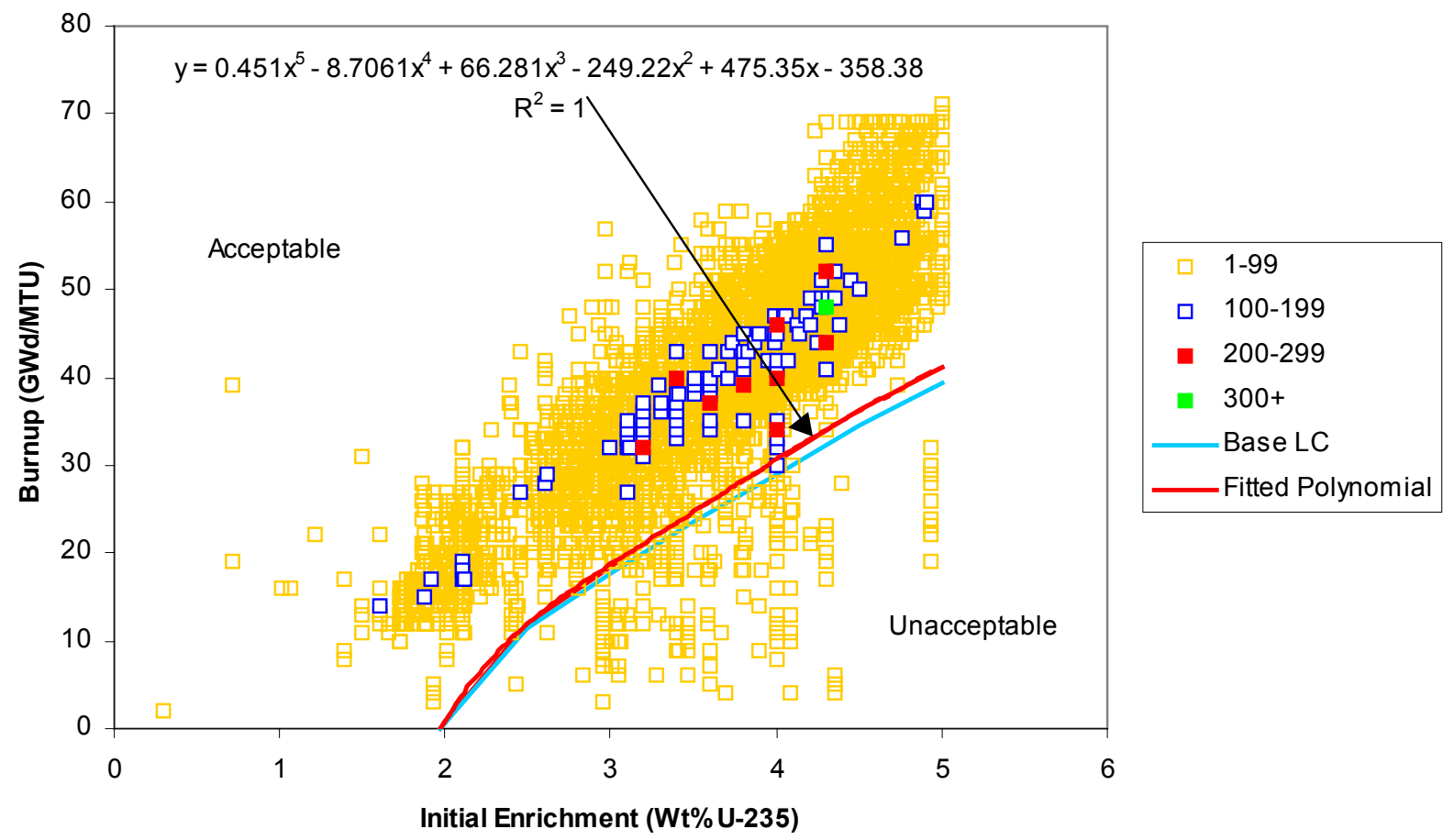

NOTE: The fitted polynomial represents the loading curve based on a five percent burnup uncertainty of the bounding curve (Base LC)

Figure A-2. Loading Restrictions for Waste Package 